\title{
Impacts of precipitation variability on plant species and community water stress in a temperate deciduous forest in the central US
}

\author{
Lianhong $\mathrm{Gu}^{*}$ \\ Environmental Sciences Division and Climate Change Science Institute, Oak Ridge National \\ Laboratory
}

Oak Ridge, TN, USA 37831

\author{
Stephen G. Pallardy \\ Kevin P. Hosman \\ Department of Forestry, University of Missouri \\ Columbia, MO 65211, USA
}

Ying Sun

Department of Geological Sciences, University of Texas at Austin

Austin, TX 78712, USA

Submitted: 22 December 2014

Revised: 24 April 2015

Re-Revised: 16 Sept 2015

This manuscript has been authored by UT-Battelle, LLC under Contract No. DE-AC05-

00OR22725 with the U.S. Department of Energy. The United States Government retains and the publisher, by accepting the article for publication, acknowledges that the United States

Government retains a non-exclusive, paid-up, irrevocable, world-wide license to publish or reproduce the published form of this manuscript, or allow others to do so, for United States Government purposes. The Department of Energy will provide public access to these results of federally sponsored research in accordance with the DOE Public Access Plan (http://energy.gov/downloads/doe-public-access-plan).

*Corresponding author:

Lianhong $\mathrm{Gu}$

Environmental Sciences Division, Building 4500N

Oak Ridge National Laboratory

Oak Ridge, TN 37831-6335.

Email: lianhong-gu@ornl.gov 


\begin{abstract}
Variations in precipitation regimes can shift ecosystem structure and function by altering frequency, severity and timing of plant water stress. There is a need for predictively understanding impacts of precipitation regimes on plant water stress in relation to species water use strategies. Here we first formulated two complementary, physiologically-linked measures of precipitation variability (PV) - Precipitation Variability Index (PVI) and Average Recurrence Interval of Effective Precipitation (ARIEP). We then used nine-year continuous measurements of Predawn Leaf Water Potential Integral (PLWPI) in a central US forest to relate PVI and ARIEP to actual plant water availability and comparative water stress responses of six species with different capacities to regulate their internal water status. We found that PVI and ARIEP explained nearly all inter-annual variations in PLWPI for all species as well as for the community scaled from species measurements. The six species investigated showed differential sensitivities to variations in precipitation regimes. Their sensitivities were reflected more in the responses to PVI and ARIEP than to the mean precipitation rate. Further, they exhibited tradeoffs between responses to low and high PV. Finally, PVI and ARIEP were closely correlated with temporal integrals of positive temperature anomalies and vapor pressure deficit. We suggest that the comparative responses of plant species to PV are part of species-specific water use strategies in a plant community facing the uncertainty of fluctuating precipitation regimes. PVI and ARIEP should be adopted as key indices to quantify physiological drought and the ecological impacts of precipitation regimes in a changing climate.
\end{abstract}

Key words: Precipitation Variability Index; Average Recurrence Interval; Effective Precipitation; Predawn Leaf Water Potential; Physiological Drought. 


\section{Introduction}

Plant physiological and metabolic functions require a continuing supply of water; yet precipitation often falls only sporadically. When it does fall, plants may not be able to use it all; some and in certain cases most of it, depending on precipitation intensity, will be lost to canopy and litter interception and evaporation, surface runoff and groundwater as soils typically have limited capacity for storing plant-available water (Helvey and Patric 1965; Chang 2012). Consider a forest with trees of rooting depth up to $1.5 \mathrm{~m}$ with sandy loam soil and a water holding capacity (i.e., plant available water; the difference between field capacity and permanent wilting point) of $15 \%$. The maximum amount of water that plants can obtain from a single precipitation event cannot exceed $225 \mathrm{~mm}$ of water no matter how substantial the event is. If we assume that after the rain stops, the forest transpires at a representative rate of $5 \mathrm{~mm} \mathrm{day}^{-1}$ (Baldocchi and Ryu 2011), the forest vegetation runs out of usable water in 45 days if there is no interim precipitation and roots are not long/deep enough to access other water sources. For vegetation with shallower rooting depths (such as on shallow soils or those with a restrictive layer of claypan or fragipan), available soil water may be depleted even sooner. These intuitive assessments are consistent with stochastic modeling studies that showed that for the same amount of rainfall during a growing season, maximal evapotranspiration is produced by some intermediate value of storm frequency (Laio et al. 2001). It is clear that both total quantity and temporal variability are important in determining the impact of precipitation regimes on soil water availability, plant water stress, and physiological and metabolic functions. 
Extensive research has been conducted on plant responses to water stress (Hsiao1973; Griffiths and Parry 2002, Mitchell et al. 2013). Numerous indices have been developed to monitor 'prolonged absence or marked deficiency of precipitation' (i.e., drought indices, Heim 2002; Dai 2011a; Zargar et al. 2011; Trenberth et al. 2014). Porporato et al. (2001) proposed measures of vegetation water stress based on the probabilistic model of soil moisture dynamics of Laio et al. (2001). They showed that storm frequency and total precipitation amount interacted to determine when minimal vegetation water stress occurs. However, few studies have examined the relationship between precipitation variability (PV) and plant water stress through long-term, direct measurements. Previous studies have investigated how PV affected the productivities of grassland ecosystems via experimental (Harper et al. 2005; Heisler-White et al. 2009) and observational approaches (Craine et al. 2012). But similar studies in forest ecosystems have been rare. Also, productivity change represents an end product of the impact of PV. To better predict ecological consequences of PV, the intermediate step, that is, the relationship between PV and plant water stress, must be understood first.

To facilitate studies of the PV - plant water stress relationship, PV and plant water stress need to be quantified. PV is determined by the distribution of precipitation intensities among individual precipitation events, hereafter referred to as intensity distribution, and by the spacing (timing and frequency) of precipitation events along the time axis, hereafter referred to as event spacing. To study the direct relationship between PV and plant water stress, a simple index that can simultaneously and adequately capture the characteristics of both intensity distribution and event spacing of PV would be beneficial. Researchers have used Coefficient of Variation (CV) and indices from the 
biodiversity literature (e.g., Shannon, Simpson, Brillouin, McIntosh) to measure PV (e.g., Fatichi et al. 2012; Bronikowski and Webb 1996). These indices describe the intensity distribution but not event spacing aspect of PV. Monti and Venturi (2007) proposed an evenness index and a weighted evenness index to study impacts of PV on crop yields but their indices have not been evaluated in-depth for broad applications.

On the plant side of the PV - plant water stress relationship, predawn leaf water potential $\left(\psi_{\mathrm{pd}}\right)$ has been commonly used by plant physiologists to measure plant water stress (Hsiao 1973; Thomas and Eamus 1999; Pallardy 2008; Breshears et al. 2009). The soil moisture-based measures of vegetation water stress proposed by Porporato et al. (2001) are useful from a hydrological point of view. However, a soil moisture-based approach is inherently limited by the large vertical variations in soil moisture and associated differential sensitivities to PV at different depths of the soil. Further, the distribution of roots at particular field sites is often unknown and most likely deeper than typical soil moisture measurements. Because of these limitations, measured soil moisture, even when integrated over some soil depth, can be poorly correlated with precipitation and may explain poorly variations in ecosystem carbon fluxes (Wu et al. 2013).

Such limitations are effectively eliminated by a $\psi_{\text {pd }}$-based approach as $\psi_{\text {pd }}$ reflects overnight equilibration of plant water potential with the soil water potential in the rooting zone. In fact, $\psi_{\mathrm{pd}}$ and its time integral have been shown to be closely associated with a broad range of plant processes, including survival and mortality in drought (Rice et al. 2004; McDowell et al. 2008; Breshears et al. 2009; McDowell and Sevanto 2010; McDowell 2011; McDowell et al. 2011; Sevanto et al. 2014; Gu et al. 2015), crop yield and tree growth (Perry et al. 1994; Giordano and Hibbs 1993; Myers 1988; Yang et al. 
2009; White et al. 2009), stomatal conductance (e.g., Running 1976; Loewentstein and Pallardy 1998; Beis and Patakis 2010), and photosynthesis (Schulze et al. 1980; Pereira et al. 1986; Aranda et al. 2004). In particular, Myers (1988) strongly advocated the use of the Predawn Leaf Water Potential Integral (PLWPI) over growing seasons to predict long-term plant growth. Given the broad range of plant functions that show such a close association, $\psi_{\mathrm{pd}}$ and PLWPI provide a key link between plant function and environmental drivers.

To use $\psi_{\text {pd }}$ and PLWPI for studying the PV - plant water stress relationship, longterm (years to decades) measurements of $\psi_{\mathrm{pd}}$ at a frequency capable of capturing the dynamic impact of precipitation regimes are needed. This is a challenge as no automated technologies are currently available and the researcher still has to get up, arrive at the site, take measurements before sunrise, and then repeat this task periodically for years and decades to come. The longest continuous record of $\psi_{\text {pd }}$ measurements in the world is probably the one maintained by Dr. David Breshears and his colleagues at University of Arizona who have been measuring $\psi_{\mathrm{pd}}$ of Pinus edulis (piñon pine) and Juniperus monosperma (juniper) at a site in New Mexico, USA since 1992 at monthly intervals (Breshears et al. 2009).

Since 2004 we have been measuring at weekly to biweekly intervals $\psi_{\mathrm{pd}}$ of half a dozen tree species of different capacities to maintain internal water status at a central US forest site (Gu et al. 2006, 2007; Belden and Pallardy 2009; Yang et al. 2010; Gu et al. 2015). This dataset (Pallardy et al. 2015) is now sufficiently long for studying the PV plant water stress relationship. Since 2004 a wide range of precipitation regimes from wet 
to exceptional drought years have occurred at this central US site, resulting in a broad spectrum of plant water stress levels. This wide range, coupled with continuous measurements of $\psi_{\mathrm{pd}}$, provides an excellent opportunity to investigate the PV - plant water stress relationship in depth.

The central US is subject to the occurrence of extreme PV. The droughts of the 1930s, 1950s and 1988-1989 had dramatic effects on the ecosystems in the region (Albertson and Weaver 1945; Jenkins and Pallardy 1995; Rosenzweig et al. 2001). Since the 1950s, the central US has experienced statistically significant shifts in precipitation regimes with heavy precipitation events becoming more frequent at the expense of less intense events (Groisman et al. 2012; Villarini et al. 2103). This observed trend is consistent with climate model projections of increased occurrence of droughts and extreme rainfall events in this region as a consequence of a warming atmosphere (Meehl and Tebaldi 2004; Janssen et al. 2014; Cook et al. 2015). Such regional climatic changes are expected to have substantial impacts on forest ecosystems (Hanson et al. 2003; Vose et al. 2012). Therefore, studying the PV - plant water stress relationship is of special importance in the central US.

This present study has two goals. The first is to develop physiologically relevant measures that can capture both the intensity distribution and event spacing aspects of PV. The second is to elucidate how variations in precipitation regimes, quantified with the measures developed, affect the actual plant water availability and comparative stress responses of tree species of different capacities to regulate their internal water status. To achieve these two goals, we will relate measures of PV to variations in $\psi_{\text {pd }}$ with time and with species. We will also investigate how these measures co-vary with temperature and 
water vapor pressure deficit anomalies. These two atmospheric variables are crucial for plant functions and their variations define the characteristics of global change-type drought (Breshears et al. 2009). Therefore, it is important to determine how they are related to precipitation variability and plant water stress. We are particularly interested in illuminating whether species-specific water use strategies in a plant community under fluctuating precipitation regimes are shaped by characteristic variations in PV and the mean precipitation rate and whether there are any tradeoffs in species' responses to different levels of PV. These questions are central for understanding and predicting ecological and physiological impacts of climate change - related shifts in precipitation regimes on plant communities.

\section{Materials and Methods}

\section{The study site and measurements}

Field data were obtained from the Missouri Ozark AmeriFlux (MOFLUX) site. This site, which has been in operation since June 2004 with a suite of meteorological and ecological instrumentation (Gu et al. 2006, 2007; Yang et al. 2010), is located in the University of Missouri's Baskett Wildlife Research and Education Area (BWREA, Lat. $38^{\circ} 44^{\prime} 39^{\prime \prime} \mathrm{N}$, Long. $\left.92^{\circ} 12^{\prime} \mathrm{W}\right)$. BWREA is within the Ozark border region of central Missouri. Second-growth upland oak-hickory forests constitute the major vegetation type at the BWREA (Rochow 1972; Pallardy et al. 1988; Belden and Pallardy 2009). Major tree species include white oak (Quercus alba L.), black oak (Q. velutina Lam.), shagbark hickory (Carya ovata (Mill.) K.Koch), sugar maple (Acer saccharum Marsh.), and 
eastern redcedar (Juniperus virginiana L.). The climate of the area is warm, humid, and continental (Critchfield 1966), with monthly mean temperature of $-1.3^{\circ} \mathrm{C}$ in January and $25.2^{\circ} \mathrm{C}$ in July and an annual total precipitation average of $1083 \mathrm{~mm}$ (National Climatic Data Center 1981 to 2010 climate normals, Columbia Regional Airport, Missouri, about $10 \mathrm{~km}$ to the northwest). Dominant soils at the site are Weller silt loam (Fine, smectitic, mesic Aquertic Chromic Hapludalf) and Clinkenbeard very flaggy clay loam (Clayeyskeletal, mixed, superactive, mesic Typic Argiudoll) (Young et al. 2001). The comparatively thin soils of these oak-hickory forests often exacerbate plant water stress when droughts occur (Bahari et al. 1985).

Precipitation was measured with a recording tipping bucket rain gauge (TR$525 \mathrm{M}$, Texas Electronics, USA) mounted at the top of the $30 \mathrm{~m}$ flux tower located at the site. Data were totaled over 30 min periods. For the years with complete site records (2005-2013), the wettest year was 2008 with an annual precipitation $328 \mathrm{~mm}$ above the long-term mean; the driest year was 2012 with an annual precipitation $460 \mathrm{~mm}$ below the long-term mean. Thus the inter-annual variability in annual precipitation was $788 \mathrm{~mm}$ during the study period. In addition to precipitation, measurements of temperature and relative humidity made at the top of the tower and at a half-hourly time step were also used in this study.

During each growing season at the MOFLUX site, we measured $\psi_{\text {pd }}$ of canopy and sapling individuals of major tree species, beginning in mid-May and ending in late October. The only exception was the year 2004 when the project started during which the first measurements began in June. Before dawn in each day, six to seven leaf samples were taken from Quercus alba, and two to four per species from Q. velutina, Acer 
saccharum, Carya ovata, Fraxinus Americana (white ash), and Juniperus virginiana. This sampling scheme roughly followed species dominance in the stand. Leaf water potential was estimated with a pressure chamber (Turner 1981; Pallardy et al. 1991). The $\psi_{\text {pd }}$ dataset used in this study have been made publically available (Pallardy et al. 2015).

\section{$\psi_{p d}$ as a measure of plant water stress}

In theory, $\psi_{\mathrm{pd}}$ reflects the result of overnight equilibration of plant water potential with the highest water potential in the rooting zone, and in uniformly moist soils, this result may be closely approached. However, internal resistance to water flow, large internal plant capacitance, growth-induced water potentials in the plant, nocturnal flow induced by high vapor pressure deficit (VPD) and open stomata, and gravitational effects may prevent true equilibration and reduce $\psi_{\text {pd }}$ below the highest root-zone water potential (Tyree 1988; Donovan et al. 1999, 2001; Tang and Boyer 2002; Kavanagh et al. 2007). As the soil dries, reduced hydraulic conductivity of the soil may also prevent equilibration (e.g., Gu et al. 2006). In contrast, trans-cuticular absorption of water by leaves associated with heavy dew formation or light mists may occasionally artificially elevate $\psi_{\text {pd }}$ values (e.g., Gouvra and Grammatikopoulos 2007). However, it must be emphasized that these effects reflect variance in the ability of $\psi_{\text {pd }}$ to closely track soil water potential and do not reflect on the validity of this parameter as an indicator of the in situ base level of water stress experienced by the plant as it enters the next diurnal period. Further, when only a portion of the soil profile can be sampled, as is the usual situation, 
$\psi_{\text {pd }}$ may at times better capture the total plant-available soil water if plants are rooted deeply (e.g., Gu et al. 2006).

Note that $\psi_{\mathrm{pd}}$ is not a direct measure of the highest water stress experienced by an individual leaf in a day. As the sun rises and transpiration starts, leaf water potential drops such that midday leaf water potential is generally lower than $\psi_{\mathrm{pd}}$ (Martínez-Vilalta et al. 2014). However, $\psi_{\mathrm{pd}}$ controls the starting point from which subsequent daytime leaf water potentials depart, which is often demonstrated by a strong linear relationship between midday leaf water potential and $\psi_{\text {pd }}$ (Martínez-Vilalta et al. 2014). More importantly, abscisic acid (ABA), the plant stress hormone that regulates stomatal conductance, is produced in roots in response to decreased soil water potential and is more closely correlated with $\psi_{\mathrm{pd}}$ than with midday leaf water potential (Loewenstein and Pallardy 1998). Also variations of $\psi_{\mathrm{pd}}$ among leaves of the same tree are minimal due to absence or near-absence of transpiration whereas during daytime, water potentials in different parts of the same tree are in disequilibrium and midday water potential can vary greatly from leaf to leaf, a phenomenon that has been known for several decades (Klepper 1968). Therefore, $\psi_{\mathrm{pd}}$ quantifies the baseline of water stress of the whole plant in a day and is a reliable, primary measure of plant water stress.

Precipitation regimes affect soil water dynamics, a topic that has been extensively studied in the hydrological literature (Laio et al. 2001). Soil moisture contents have been monitored at multiple depths at the MOFLUX site. However, the temporal dynamics of soil moisture heavily depends on the depth at which it is measured. As a result, any relationship between PV and soil moisture and its implication for plant physiology will 
certainly be depth-specific, limiting the generality of any conclusion that can be drawn. This problem may be abated by using the total soil moisture of the rooting zone. Unfortunately, the availability of total soil moisture is generally hampered by the difficulty of measuring moisture in deep soil and by imprecise knowledge of rooting depth at any particular site. Also, species responses to PV cannot be differentiated with soil moisture measurements. In contrast, $\psi_{\mathrm{pd}}$ is an integrated measure of soil water availability that is specific to individual plant species and determines the starting point from which plant water stress develops during daytime. Thus in this study, we will use $\psi_{\text {pd }}$ as a measure of water stress for different plant species. We will relate this stress measure to different measures of PV, which are introduced below.

\section{Quantifications of precipitation variability}

All existing indices that have been used to measure PV and known to us have shortcomings. For example, CV (e.g., Fatichi et al. 2012) only quantifies intensity distribution; event spacing has no impact on its value. Consider two hypothetical patterns of precipitation events during a 60-day period (Fig. 1a and b). Both patterns contain 10 rainy days at the same rate of $10 \mathrm{~mm} \mathrm{day}^{-1}$ and thus have the same mean precipitation rate of $1.67 \mathrm{~mm}^{-1} \mathrm{day}^{-1}$ over this 60-day period. However, in Pattern I (Fig. 1a), the rainy days concentrate in the first 10 days of the 60-day period, leaving the next 50 days dry. In Pattern II (Fig. 1b), the rain occurs every 6 days within the 60-day period, leaving only 5 dry days in between each event. Obviously, plants should experience more water stress over the total 60-day period under Pattern I than under Pattern II. Yet, CV would give 
exactly the same value for both patterns (Fig. 1c), because it is not affected by event spacing. Indices borrowed from the biodiversity literature (e.g., Shannon, Simpson, Brillouin, McIntosh) to measure PV (e.g., Bronikowski and Webb 1996) suffer from the same problem as CV does and cannot adequately quantify PV (the values of the Shannon index for the two examples above are given in Fig. 1c). Monti and Venturi (2007) proposed an interesting idea that avoids the problem of $\mathrm{CV}$ and indices borrowed from biodiversity literature as a measure of PV. Basing their idea on cumulative precipitation, they developed indices that were sensitive to both intensity distribution and event spacing. As shown below, Monti and Venturi's approach also has some potential shortcomings but can be improved. Recently we built upon these previous studies and developed our own measures of PV. The indices described here were originally introduced in Gu et al. (2015). For the purpose of completeness, we describe them again in the present paper.

We consider a time series of precipitation measurements $\left\{p_{1}, p_{2}, \ldots, p_{n}\right\}$. It is assumed that the $p_{i}$ values, $i=1, \ldots, n$, are measured at regular intervals. The intervals can be hourly, daily, or weekly, or longer, depending on the intended use of resultant indices. For the purpose of this study, we assume that the $p_{i}$ values are measured daily in a unit of $\mathrm{mm} \mathrm{day}^{-1}$.

The Precipitation Variability Index (PVI). From $\left\{p_{1}, p_{2}, \ldots, p_{n}\right\}$, a time series of cumulative precipitation measurement $\left\{C_{1}, C_{2}, \ldots, C_{n}\right\}$ as well as the mean precipitation rate for the whole time series are computed:

$C_{i}=\sum_{j=1}^{i} p_{j}, i=1, \ldots, n$. 
$\bar{p}=\frac{\sum_{i=1}^{n} p_{i}}{n}$

From the mean precipitation rate $\bar{p}$, we construct another time series $\left\{E_{1}, E_{2}, \ldots, E_{n}\right\}$ consisting of elements:

$E_{i}=i \bar{p}, i=1, \ldots, n$.

For convenience, we call $\left\{E_{1}, E_{2}, \ldots, E_{n}\right\}$ the time series of cumulative mean. When the precipitation is perfectly uniform (i.e., all $p_{i}$ s have the same value), the time series of cumulative measurement and cumulative mean are identical. Monti and Venturi (2007) used the difference between the two time series to characterize the 'evenness' of precipitation through the following two expressions:

$U=\sqrt{\frac{\sum_{i=1}^{n}\left(C_{i}-E_{i}\right)^{2}}{n}}$

$W=\frac{U}{\bar{p}}$

Monti and Venturi (2007) called $U$ and $W$ the evenness index and weighted evenness index, respectively. The unit of $U$ is the same as $C_{i}$ and $E_{i}$, which is the amount of precipitation ( $\mathrm{mm}$, as used in the present study); that of $W$ is time (days, as used in the present study) because the mean precipitation rate $\bar{p}$ is in a unit of mm day ${ }^{-1}$. Thus both $U$ and $W$ are not dimensionless.

However, we found that both $U$ and $W$ did not explain well the inter-annual variability of $\psi_{\mathrm{pd}}$ measured at the MOFLUX site. In an attempt to improve over $U$ and $W$, a scale-independent, dimensionless index is formed by first constructing a time series 
$\left\{R_{1}, R_{2}, \ldots, R_{n}\right\}$ consisting of the ratio of the cumulative precipitation to the cumulative mean:

$R_{i}=\frac{C_{i}}{E_{i}}$

The standard deviation of the ratio is then used as a Precipitation Variability Index (PVI):

$P V I=\sqrt{\frac{\sum_{i=1}^{n}\left(R_{i}-\bar{R}\right)^{2}}{n}}$,

where,

$\bar{R}=\frac{\sum_{i=1}^{n} R_{i}}{n}$

PVI is dimensionless because $R_{i}$ is dimensionless. PVI has a value of zero for perfectly uniform precipitation.

The two hypothetical patterns of precipitation events discussed above illustrate well how PVI works and its difference from other previously used indices, including the evenness index $U$ and the weighted evenness index $W . U, W$ and PVI are all able to differentiate between these two patterns while CV and Shannon Index cannot. The values of $U, W$ and PVI are larger for Pattern I than for Pattern II because the cumulative curve of Pattern I is further away from the cumulative mean line than the cumulative curve of Pattern II is (Fig. 1c).

Although $U$ and $W$ are sensitive to event spacing, they are not stable indices for a particular pattern of precipitation. Fig. 2 shows $U, W$ and PVI as a function of duration of index evaluation for Pattern II (Fig. 1c only shows the values of these indices for a fixed 
duration of 60 days). All three indices oscillate initially at short durations (because of the on/off nature of precipitation events). However, as the duration lengthens, the magnitude of oscillation of PVI rapidly decreases and its value stabilizes while $U$ and $W$ continue to oscillate at the same magnitude. This characteristic of $U$ and $W$ makes it difficult to associate their values with any particular patterns of precipitation intensity distribution and event spacing, thus decreasing their usefulness in measuring PV. This point will be further discussed later in the analysis of $\psi_{\mathrm{pd}}$ measurements.

\section{The Average Recurrence Interval of Effective Precipitation (ARIEP). Plant}

water stress develops when precipitation events are too sparse. Thus the intervening time between two adjacent precipitation events could be used to construct a measure of PV. However, all precipitation events are not equal. Very light precipitation may just wet the leaves of the canopy or the overlaying litter layer of the floor and evaporate rapidly back to the atmosphere. For a precipitation event to contribute directly to reducing plant water stress and improving transpiration and thus photosynthesis, it has to be intense enough to penetrate the canopy and litter layer and wet the mineral soil where the added moisture can be then extracted by plant roots for use in plant metabolic and physiological functions. Ecologists who study arid and semiarid ecosystems often use the concept of 'effective precipitation' to denote such precipitation events (Noy-Meir1973; Porporato et al. 2002). While complex canopy rainfall interception models are available (e.g., van Dijk and Bruijnzeel 2001), a simple ecologically-based concept of effective precipitation serves the purpose of this paper which focuses on time scales longer than a day. Here we use a threshold precipitation rate $\left(p_{t}\right)$ to identify effective precipitation events. We define an interval of effective precipitation as an interval flanked by two adjacent precipitation 
events that have precipitation rates larger than $p_{t}$. The average of all intervals of effective precipitation should be an ecologically relevant measure of PV. Although Gu et al. (2015) called this average 'Mean Effective Precipitation Interval' (MEPI), its definition is actually consistent with that of 'Average Recurrence Interval' commonly used by hydrologists (Bonnin et al. 2006). To avoid confusion, we rename MEPI of Gu et al. (2015) to ARIEP.

Mathematically, ARIEP is calculated as

$$
A R I E P=\frac{\sum_{i=1}^{k} L_{i}}{k} .
$$

Here, $L_{i}$ is the number of days of the $i^{\text {th }}$ interval of effective precipitation during a given period of observation for which ARIEP is calculated and $k$ is the total number of intervals of effective precipitation. For the purpose of calculating ARIEP, the precipitation time series $\left\{p_{1}, p_{2}, \ldots, p_{n}\right\}$, is assumed to follow and is followed with an effective precipitation event, i.e., $p_{0}$ and $p_{n+1}$ both have values larger than $p_{t}$. A feature of ARIEP is that precipitation rates are used as a categorical variable. Once $p_{t}$ is determined, how much their values are above or below $p_{t}$ do not affect ARIEP. In contrast, values of precipitation rates affect PVI. Thus ARIEP and PVI are complementary measures of PV.

Positive temperature anomaly integral (PTAI) and water vapor pressure deficit integral (VPDI) 
Atmospheric temperature and VPD are key environmental variables that affect plant physiology. They are also intimately related to precipitation regimes. To evaluate their roles in the PV - plant water stress relationship, we formulated PTAI and VPDI:

$P T A I=\sum_{i=1}^{n} \max \left(T_{i}-T_{c i}, 0\right) / 48$,

$V P D I=\sum_{i=1}^{n} V P D_{i} / 48$

In Eq. 10, $T_{i}$ is the observed half-hourly temperature at the time step $i$ and $T_{c i}$ is the daily mean temperature climate normal of the day during which the time step $i$ occurs. ' $\max$ ' in the right hand side of Eq. 10 means that in any day only those half-hourly temperatures above the normal of that day (i.e., positive temperature anomaly) is included in the calculation of PTAI. The daily mean temperature climate normals were computed by the US National Climatic Data Center (NCDC) with observations of the period 1981 to 2010 at the Columbia Regional Airport (less than 10km to the northwest of the MOFLUX site). The half-hourly temperature data were from measurements made at the top of the MOFLUX tower. In Eq. 11, $V P D_{i}$ is the VPD in the unit of $\mathrm{kPa}$ at $i$. The VPD values were half-hourly and computed from half-hourly temperature and relative humidity observed at the top of the tower. The division by 48 in Eqs. 10 and 11 allows PTAI and VPDI to be expressed in a unit of ${ }^{\circ} \mathrm{C}$ day and kPa day, respectively.

\section{Data processing and analyses}

Measurements in the growing seasons of 2005 to 2013 were used in this study; data in 2004 covered only part of the growing season and therefore were excluded. Although 
growing-season data were used, how precipitation regimes affected the interannual variations in the timing and length of growing seasons is beyond the scope of the present study. Therefore, we used day 120 and day 300 as the nominal start and end of the growing season respectively for all years based on the seasonal patterns of leaf area index (LAI) measured at the site (data not shown). Using the same dates to mark the growing season for all years eliminated uncertainties that may be caused by using different lengths of period to calculate PVI, ARIEP, PTAI, VADI and temporal integrals of $\psi_{\text {pd. }}$. While the onset and senescence of vegetation activities varied somewhat from year to year, the day 120 was sufficiently early and day 300 sufficiently late such that no significant vegetation growth occurred beyond these two dates.

Half-hourly measurements of precipitation rate were summed into daily values, which were then used to determine growing-season PV. We linearly interpolated the weekly to biweekly measurements of $\psi_{\text {pd }}$ for days that predawn measurements were not made. It was assumed that the $\psi_{\text {pd }}$ on day 120 and on day 300 was zero so that any day before the first (mid-May) or after the last measurement (late October) could be properly interpolated. This assumption is a reasonable approximation because our first and last measurements of $\psi_{\text {pd }}$ were always close to zero even during years when severe drought occurred as all droughts were terminated by end-season precipitation. We then calculated the area formed by the zero line and the seasonal curve of $\psi_{\mathrm{pd}}$; this area is the Predawn Leaf Water Potential Integral (PLWPI) and has a unit of MPa day (Myers 1988). We examined the changes of PLWPI with $\bar{p}$, PVI, ARIEP, PTAI and VPDI for each species and for the community. Relationships among $\bar{p}$, PVI, ARIEP, PTAI and VPDI were also investigated. To determine the threshold $p_{t}$ of the effective precipitation rate for the 
calculation of ARIEP, we experimented with $p_{t}$ from 0 to $15 \mathrm{~mm} \mathrm{day}^{-1}$ at a step of $1 \mathrm{~mm}$ day $^{-1}$. We found that $p_{t}=5 \mathrm{~mm} \mathrm{day}^{-1}$ resulted in the best fit (in terms of $\mathrm{R}^{2}$ ) between PLWPI and ARIEP at both species and community levels. The fitness was not particularly sensitive to small variations in $p_{t}$ around $p_{t}=5 \mathrm{~mm} \mathrm{day}^{-1}$; i.e., a $p_{t}$ of 4.5 to $5.5 \mathrm{~mm} \mathrm{day}^{-1}$ produced $\mathrm{R}^{2}$ similar to $p_{t}=5 \mathrm{~mm}$ day $^{-1}$. Therefore $5 \mathrm{~mm}^{-1 a y}{ }^{-1}$ was used as the threshold to differentiate effective precipitation events $\left(p \geq 5 \mathrm{~mm} \mathrm{day}^{-1}\right)$ from those non-effective ones $\left(p<5 \mathrm{~mm} \mathrm{day}^{-1}\right)$. For convenience, ARIEP with $p_{t}=5 \mathrm{~mm} \mathrm{day}^{-1}$ is denoted as ARIEP5. The community PLWPI was the mean of species PLWPI weighted with species abundance based on their relative basal area in the stand.

Hsiao (1973) suggested a guideline for evaluating plant water stress based on leaf water potential measurements. According to that guideline, plants are considered to be under mild stress when plant water potential is several tenths of a MPa below corresponding values in well watered plants under mild evaporative demand; under moderate stress when water potential declines below this range but remains above -1.5 $\mathrm{MPa}$; and under severe water stress as water potential declines below -1.5 MPa. This guideline was applied in this study to establish plant water stress levels based on $\psi_{\text {pd }}$ measurements.

For regression analyses, the Akaike's Information Criterion corrected for finite sample size (AICc, Anderson 2010) was used to select for the most parsimonious model (i.e., the model that explains the maximum amount of variation with the smallest number of parameters). As AICc is only a relative measure of goodness of fit (i.e., it is only meaningful in comparisons among different AICc values) and cannot be applied for comparisons when data used in the fittings are different, the $\mathrm{R}^{2}$ and root mean square 
error (RMSE) were also displayed to show the variance explained and the absolute goodness of fit, respectively. For all regressions, the statistical power of the fitting was given through the F test. All curve fittings in this study used in-house software that has been developed over the years and supported efforts of parameter estimation such as those of LeafWeb (leafweb.ornl.gov, Gu et al. 2010; Sun et al. 2014).

\section{Results}

Seasonal dynamics of $\psi_{\mathrm{pd}}$ for all species were shown in Fig.3 for three selected, contrasting years (2009, wet; 2006, moderate drought; 2012, severe drought). Under wet conditions, values of $\psi_{\mathrm{pd}}$ for different years and for all species were all close to zero, indicating equilibration with wet portions of the soil (Fig. 3a, b, and c). In the intermediate drought of 2006, there were large differences among species in their seasonal dynamics of $\psi_{\mathrm{pd}}$, which suggests that these species differed in their capacity to maintain hydration status (Fig. 3b). During the peak drought of 2012, the $\psi_{\text {pd }}$ of all species approached or even went below $-4 \mathrm{MPa}$ (Fig. 3c). Thus according to the guideline of Hsiao (1973), the $\psi_{\text {pd }}$ measurements at the MOFLUX site covered a broad spectrum of plant water stress, providing an ideal dataset for evaluating the ecological and physiological impacts of precipitation regimes.

Both at the species (Figs. 4-6) and community (Fig. 7) levels, PLWPI is nonlinearly related to $\bar{p}$ (Figs. 4 and 7a), PVI (Figs. 5 and 7b) and ARIEP5 (Figs. 6 and 7c). PLWPI increases with $\bar{p}$ and decreases exponentially with PVI; it tends to level off at high $\bar{p}$ and PVI. While the dependence of the species and community PLWPI on $\bar{p}$ is 
evident, points are scattered rather loosely in the PLWPI $-\bar{p}$ relationship. In contrast and except for the year 2006 (cf. the circled point in Figs. 4 and 5 and the point labeled '06' in Fig.7), all years tightly collapse into a single curve for all species (Figs. 5) as well as for the community (Fig. 7b) in the PLWPI - PVI relationship. PLWPI decreases with ARIEP5 and the shape of decrease varies among species ranging from white oak's almost linear trend (Fig. 6a) to white ash's near exponential decrease (Fig. 6b). The PLWPIARIEP5 relationship for all species and community is much tighter than the PLWPI $-\bar{p}$ relationship is. It is also tighter than the PLWPI - PVI relationship if the year 2006 is included while the opposite is true when the year 2006 is excluded.

Although the year 2006 departs from other years in the general PLWPI - PVI relationship (Figs. 5 and 7b), it is within the overall patterns of PLWPI against $\bar{p}$ (Figs. 4 and 7a) or ARIEP5 (Figs. 6 and 7c). This year happens to have both low $\bar{p}$ and low PVI but intermediate ARIEP5 (cf. the circled point in Figs. 4 and 5 and the point labeled '06' in Fig. 7). It is a year with a moderate drought (Fig. 3b). Its PVI is relatively low because several small rain events occurred during the growing season and these events were fairly evenly spaced temporally, which can be deduced from the repeated interruptions in the seasonal patterns of $\psi_{\mathrm{pd}}$ of different species (Fig. 3b) as well as its intermediate value of ARIEP5 (see the point labeled with '06' in Fig. 7c). The presence of 2006 as an outlier in the otherwise tight PLWPI - PVI relationship suggests that PVI is a strict variability measure and contains minimal information about precipitation amount and must be used in conjunction with $\bar{p}$ while ARIEP5 can be applied independently.

The driest year during the study period is 2012 (Fig. 3c). It has the lowest $\bar{p}$ (Fig. 7a) and highest PVI (Fig. 7b) and largest ARIEP5 (Fig. 7c) among all years studied. This 
year also has the lowest PLWPI for nearly all species (not labeled but can be easily seen in Fig 6) and for the community as a whole (Fig. 7). The only exception is shagbark hickory which has similar PLWPI for 2006, 2007 and 2012. Although 2012 is an exceptional drought year, it appears to follow general relationships of PLWPI against either PVI or ARIEP5 because this drought is exhibited as both high PVI and large ARIEP5, in contrast to year 2006.

To further investigate how precipitation regimes affected PLWPI, we experimented with the following equations to fit the relationships of PLWPI with different indices for all species and also for the community. These equations were selected after many trials and errors and were based on the scattering patterns shown in Fig. 4 to 7.

$$
\begin{aligned}
& P L W P I=a-\frac{b}{x}, \\
& P L W P I=c+d e^{-e x}, \\
& P L W P I=f+\frac{g}{\left(1+e^{-\frac{x}{h}}\right)^{k}} .
\end{aligned}
$$

Here $x$ can be either $\bar{p}$, PVI or ARIEP5 and $a, b, c, d, e, f, g, h$ and $k$ are empirical constants. One variant of Eq. (13) and three variants of Eq. (14) were also tested. In the variant of Eq. (13), $c$ was fixed to 0, reducing its number of free parameters to the same as Eq. (12). The first variant of Eq. (14) fixed $f=0$, reducing its number of free parameters to 3; the second kept $f, g$, and $h$ but fixed $k=1$, also reducing the number of free parameters to 3 ; the third set fixed $f=0$ and $k=1$, reducing the number of free parameters to 2 . Thus in total, seven equations were tested. We fitted all seven equations 
for each index and then selected the most parsimonious equation with the AICc criterion. According to AICc, the most parsimonious equation for $\bar{p}$, PVI or ARIEP5 was Eq (12), (13) and (14), respectively. It turned out for $\bar{p}$, the $\mathrm{R}^{2}$ and RMSE resulted from using Eq (14) were the same as those from using Eq (12) while for PVI, Eq. (13) gave the same $\mathrm{R}^{2}$ and RMSE as Eq. (14). These tests showed that over-fitting did not occur and the differences in the goodness of fit of PLWPI as a function of $\bar{p}$, PVI or ARIEP5 were due to the differences in the explanatory power of these indices for PLWPI, not due to the complexity of the functions or the number of free parameters. The final fitting coefficients and RMSE are given in Table 1 and the $\mathrm{R}^{2}$ and statistical significance ( $p$ value) were given in corresponding figures from Fig. 4 to 7.

With the year 2006 included, more variance in PLWPI is explained by ARIEP5 (92-99\%) than by either PVI (51-89\%) or $\bar{p}(70-89 \%)$ for all species and also for the community (Figs. 4-7). This pattern is consistent with RMSE, showing that ARIEP5 always has the smallest RMSE among the three indices (Table 1). The lowest variance explained is for shagbark hickory and the highest variances explained are sugar maple and white oak. ARIEP5, PVI and $\bar{p}$ explain 97, 77 and 88\%, respectively, for the community PLWPI. With 2006 excluded, PVI becomes the best predictor of PLWPI and explains nearly all variance (>95\%) in PLWPI for all species and community. These quantitative statistical differences among the three indices can be confirmed by visually examining the general scattering patterns of points in Fig. 4 to 7 , i.e., points in the $\bar{p}-$ PLWPI plots are generally more loosely scattered around the fitted curves than those in the ARIEP5 - PLWPI plots (compare Fig. 4 verse 6 or Fig. 7a verse 7c). We also tested 
the fittings with and without the exceptional drought year 2012 included and found no significant difference in term of variance explained.

PLWPI is weakly correlated with PTAI (Fig 8a) but strongly and significantly with VPDI (Fig. 8b, $R^{2}=0.83, p=0.005$ ). As expected, precipitation regimes affected PTAI and VPDI. Much of the variances in PTAI and VPDI can be explained by $\bar{p}$ (Fig. 9a and b), PVI (Fig. 9c and d), and ARIEP5 (Fig. 9e and f). ARIEP5 worked particularly well, explaining nearly $90 \%$ of the variance in VPDI. Similarly to PLWPI, the relationships of $\bar{p}$, PVI and ARIEP5 with VPDI are generally stronger and more statistically significant than those with PTAI. These results further suggest the potentials of PVI and ARIEP5 as physiologically relevant measures of precipitation regimes.

Among the six species examined, white oak and white ash represent two extremes in the plant - precipitation relationship (Fig. 10). For the same $\bar{p}$, PVI, or ARIEP5, white oak has the highest and white ash has the lowest PLWPI. The curves for the remaining four species are closely distributed in between those for the two extremes. The PLWPI- $\bar{p}$ curves nearly parallel each other (Fig. 10a). In contrast, the PLWPI-PVI curves (Fig. 10b\&d) as well as those for ARIEP5 (Fig. 10c) show more curvature variations. This contrast suggests that PVI and ARIEP5 may contain additional information independent from $\bar{p}$ in characterizing variations in PLWPI.

The existence of relatively strong relationships of PLWPI with $\bar{p}$, PVI and ARIEP5 makes it possible to answer the following question: how might plant species differ in the sensitivities of their internal water status to water stress induced by variations 
in precipitation regimes? This question can be answered by investigating the derivatives of PLWPI with respect to $\bar{p}$, PVI and ARIEP5, respectively:

$\frac{d P L W P I}{d \bar{p}}=\frac{b}{\bar{p}^{2}}$.

$\left|\frac{d P L W P I}{d P V I}\right|=d e e^{-e P V I}$,

$\left|\frac{d P L W P I}{d M E P I 5}\right|=-\frac{g k}{h} \frac{e^{-\frac{M E P I 5}{h}}}{\left(1+e^{-\frac{M N E I 5}{h}}\right)^{1+k}}$,

In Eqs. 16 and 17, absolute values are used since only magnitudes matter for sensitivity analyses (the negative sign appears in Eq. 17 because $g$ is always negative, see Table 1). As PLWPI varies nonlinearly with $\bar{p}$, PVI and ARIEP5, its sensitivities to them are not constant. Fig. 11 shows the derivatives of PLWPI as a function of $\bar{p}$ (Fig. 11a), PVI (Fig.11b \&d), and ARIEP5 (Fig. 11c). PLWPI is more sensitive to changes in $\bar{p}$ and PVI at low than at high $\bar{p}$ and PVI. In contrast, the peak sensitivity of PLWPI to ARIEP5 appears at some intermediate values of ARIEP5, depending on species. It is interesting that all PLWPI-PVI sensitivity curves cross roughly at PVI $=0.6$ at which value all species are equally sensitive to variations in PVI. For ARIEP5, the sensitivity curves cross at around 8 days. The extremities of white oak and white ash in the spectrum of plant - precipitation relationship are again demonstrated in sensitivity analysis. When PVI (ARIEP5) is less than about 0.6 ( 8 days), white oak is the least sensitive and white ash is the most sensitive to changes in PVI (ARIEP5). However, once PVI (ARIEP5) exceeds about 0.6 (8 days), these two species switch positions with white oak being the most sensitive and white ash being the least sensitive to changes in PVI (ARIEP5). This switching in sensitivity positions may indicate that some tradeoffs exist in species 
responses to low and high precipitation variability. The remaining species are bracketed by these two species across the full ranges of PVI and ARIEP5.

For any given value of $\bar{p}$, white ash always tends to have higher sensitivity to changes in $\bar{p}$ than other species and the sensitivity curves for other species almost overlap (Fig. 11a). Compared to the sensitivity curves of PVI and ARIEP5, those of $\bar{p}$ are very close to each other and show much less variations across species over the range of $\bar{p}$. Thus, plant species are less differentiated in their sensitivities of PLWPI to $\bar{p}$ than to PVI or ARIEP5.

ARIEP5 and PVI improve upon the evenness index U and the weighted evenness index W of Monti and Venturi (2007). In contrast to the tight relationships of PLWPI with ARIEP5 and PVI, both U and W poorly explain the variations in PLWPI for the community (Fig. 12) as well as for all species examined individually (data not shown). Monti and Venturi (2007) only examined the effects of $U$ and $\mathrm{W}$ on maize and sugar beet yields. It is possible that $\mathrm{U}$ and $\mathrm{W}$ might work in managed agricultural systems but not in unmanaged ecosystems.

\section{Discussion}

The substantial predictive powers of ARIEP (ARIEP5 at the MOFLUX site) and PVI for PLWPI suggest that these indices are closely related to physiological and metabolic functions of plants. Their correlation with PTAI and VPDI indicate that they are capable of implicitly capturing the impacts of high temperature and VPD, which are intimately linked to water availability, on plant functions. Taking together, we argue that ARIEP 
and PVI are easily measured, important indices with applications in studying the impacts of precipitation regimes on plant, vegetation, and terrestrial ecosystem functions.

Why ARIEP5 has better overall performance than PVI (and also $\bar{p}$ ) at the MOFLUX site? Of course, there is one more parameter in the equation for ARIEP5 (Eq. 14) than for PVI (Eq. 13). However no apparent over-fitting or under-fitting occurs in either the PLWPI - ARIEP5 relationship (Figs. 6 and 7c) or the PLWPI - PVI relationship (Figs. 5 and $7 \mathrm{~b}$ ) which we confirmed with parameter/function selection tests and AICc. The need for one more parameter in Eq. 14 only reflects the slightly more complicated overall shape of the PLWPI - ARIEP5 relationship. It is also true that an optimal process is conducted to select for $p_{t}=5 \mathrm{~mm} \mathrm{day}^{-1}$. However, an optimal $p_{t}$ alone cannot guarantee the performance of ARIEP. Often less precipitation means more sporadic precipitation (i.e., higher precipitation variability; Rigby and Porporato 2010), suggesting precipitation variability and quantity are not completely mutually independent. This point is demonstrated in Fig. 13 which shows that both ARIEP5 and PVI are nonlinearly correlated with $\bar{p}$. For PVI, the correlation is caused mainly by two extremely low $\bar{p}$ years (2007 and 2012); once these two years are excluded, the correlation becomes weak. In contrast, ARIEP5 shows strong correlation with $\bar{p}$ across the full range of $\bar{p}$. Thus ARIEP5 contains more information about $\bar{p}$ than PVI does, or equivalently, PVI is more strictly a variability index than ARIEP5 is.

The relatively greater independence of PVI and $\bar{p}$ can also been seen from the situation when PVI = 0. According to Eq. 13, PLWPI is largest (least water stress) at PVI $=0$. Zero PVI is obtained when precipitation events are perfectly uniform. This would also include the case no precipitation occurs at all in the growing season, a case of 
extreme water stress. In this case, an infinitely negative PLWPI is obtained with Eq.12 as $\bar{p}=0$. Thus PVI must be always applied in conjunction with $\bar{p}$ while ARIEP5 may be applied as a standalone index as it already contains substantial information about $\bar{p}$. Although the performance of ARIEP5 is robust to small perturbation in the effective precipitation threshold $p_{t}=5 \mathrm{~mm} \mathrm{day}^{-1}$ at the MOFLUX site, the value of $p_{t}$ is likely sitespecific, i.e., ARIEP4 $\left(p_{t}=4 \mathrm{~mm} \mathrm{day}^{-1}\right)$ or ARIEP6 $\left(p_{t}=6 \mathrm{~mm} \mathrm{day}^{-1}\right)$ or some other threshold quantity may work better at other sites. We hypothesize that sites with higher leaf area index (LAI) or thicker floor litter layers have larger $p_{t}$ as canopies with higher LAI or thicker litter layers require more intense precipitation to result in soil wetting. Precipitation statistics might also contribute to differences in $p_{t}$ between sites. We hope that other researchers can apply the approach herein to test the general merit of these indices in the study of impacts of precipitation regimes on plant species and community water stress. While the empirical coefficients in Eqs. 12-14 and the value of $p_{t}$ may vary from site to site, we expect the general relationships reported in this study are likely valid across sites.

At the MOFLUX site, years of high PLWPI (less negative, low water stress) were associated with high mean precipitation rate $(\bar{p})$, low variability in (and thus more frequent) precipitation (PVI), and a reduced interval between effective rainfall events (ARIEP5). From a plant community and biophysical perspective, a high $\bar{p}$ reflects a soil that is well-wetted, providing ample regions of high rhizosphere water potential with which plants could equilibrate overnight, thus keeping PWLPI high. Further, the slightly flatter relationship between PLWPI and ARIEP5 compared with that of PVI at low values of PVI and ARIEP5 (cf. Figs. 5 vs 6 and 7b vs c) suggests that the more frequent wetting 
of the soil implied by smaller ARIEP5 values more often elevates the moisture content of the soil to some depth below which soil moisture remains unchanged. Root water potential equilibration with these topsoil layers overnight may differentially elevate predawn leaf water and explain the deviation of the two responses (e.g., Fig. 11). Disappearance of differentially wetted shallow layers as PVI and ARIEP5 increase likely equalizes rates of decline as shown in the PLWPI and PVI-ARIEP5 relationships at intermediate values. It is also worth noting that, although admittedly dominated by one very severe drought year, the relationships between PLWPI and PVI and ARIEP5 flatten considerably at extreme values of the latter two variables, suggesting that PLWPI is somehow moderated under severe drought. The most likely explanation for this response is reduction of soil water loss during severe drought attributable to transpiration suppression via stomatal closure. An uncertainty in explaining the responses of PLWPI to different measures of precipitation regimes is how root uptake of soil moisture and hydraulic redistribution might compensate for variations in soil moisture with depth and time, a potentially fruitful area for future investigation.

Inter-species differences in the responses of PLWPI to PVI, $\bar{p}$, and ARIEP5 were clearly evident. White oak and white ash showed departures from the responses of other species. These two species are known to occupy the two ends of the isohydric to anisohydric continuum within the species studied here (Gu et al. 2015). Overall, white ash, a relatively anisohydric species among the ones studied here, demonstrated greater decline in PLWPI as all variables reflected its greater site water stress, suggesting that this species was more shallowly rooted than others and endured greater seasonal water stress. This pattern of response is consistent with the reported drought sensitivity of this 
species in the literature (e.g., Schlesinger 1990). To some extent, this attribute might be associated with the generally smaller average size of white ash tree population on the site ( $4.8 \mathrm{~cm} \mathrm{dbh}$ - diameter at breast height - for all plants $>1.3 \mathrm{~m}$ height) compared with the two oak dominants ( $24.8 \mathrm{~cm}$ and $13.4 \mathrm{~cm}$ dbh for white and black oak, respectively). However, mean diameter of sugar maple was similar to that of white ash $(5.8 \mathrm{~cm}$ dbh $)$ and thus the substantial different responses of white ash exhibited in the present study were likely not entirely attributable to tree size/age. Hence our study suggests that it is also possible to classify the potential vulnerability of plant species to drought-related injuries (e.g. potential hydraulic dysfunction, unfavorable trends in carbon balance due to inhibition of photosynthesis, elevated susceptibility to biotic attack due to weakened defense, and mortality) based on the response of its PLWPI to ARIEP or PVI. The PLWPI of plant species at the MOFLUX site shows a wide spectrum of responses to variations in ARIEP and PVI. While belowground studies on plant root functions are indispensable, they are much more difficult to carry out than measuring $\psi_{\mathrm{pd}}$ and calculating PLWPI. Our results suggest that it may be possible to use the relationships of PLWPI with ARIEP and PVI as a proxy for water use niches occupied by individual species.

Our studies show that plant species' sensitivities to precipitation variability are not constant and vary with the ranges of precipitation variability as measured by PVI and ARIEP. Species that are more sensitive at low precipitation variability may become less sensitive at high precipitation variability and vice versa. This finding has some implications. First, no single water use strategy is optimal across the full spectrum of precipitation variability and optimal water use strategies vary according to the positions 
within this spectrum. Consequently, there are tradeoffs in any particular water use strategies. Second, co-occurring species in a plant community can evolve complementary water use strategies according to their niches in the community. Third, when comparing impacts of precipitation regimes across species, it is important to examine the spectrum of precipitation variability in full.

ARIEP and PVI are not drought indices, per se, and are not designed to replace them. Drought indices have been formulated to quantify a lack of precipitation as compared to normal (Heim 2002; Dai 2011a; Zargar et al. 2011; Trenberth et al. 2014). They consider both the supply and demand sides of the water budget equation. In contrast, ARIEP and PVI are only limited to the statistical, physiologically-relevant description of precipitation regimes. Nevertheless, recent studies have highlighted shortcomings of existing drought indices (Orlowsky and Seneviratne 2013; Trenberth et al. 2014). It is possible that by integrating ARIEP and PVI with drought indices such as Palmer Drought Severity Index (PDSI, Dai 2011b), droughts can be described in a way that better serves the increasing need of understanding and predicting plant-precipitation relationships in a changing world.

A starting point towards this direction might be to consider how droughts are classified. Droughts are currently classified into meteorological drought, agricultural drought and hydrological drought. Meteorological drought is defined as a duration of months to years with below-normal precipitation; agricultural drought refers to a period with dry soils, particularly dry topsoils, that reduce crop yield; and hydrological drought is a period with below-normal river streamflow, water storage in aquifers, lakes and reservoirs (Dai 2011a). These definitions are useful for water resource management but 
are not conducive to understanding and predicting impacts on ecosystem function. From a perspective of plant water relation, a fourth type could be considered: physiological drought, a term that has been used previously (e.g., Mitchell et al. 2013). Based on our results, physiological drought can be conveniently defined as a period when predawn leaf water potential drops below certain threshold (for example, below which leaf wilting occurs), much like the severe water stress threshold established by Hsiao (1973). It could be defined at species or community levels. There are some similarities in the definitions of agricultural and physiological droughts as both are linked to the impacts of meteorological droughts. However, wild plant species experience more stressful environments than crops do and may have evolved different root architectures and adaptation strategies. Also, human intervention may prevent agricultural drought if a region is experiencing meteorological but not hydrological drought. Thus it is desirable to differentiate physiological drought from agricultural drought. A time-evolving ARIEP or PVI could be used to predict the expected time when physiological drought will occur as a result of preceding precipitation regimes.

Climate change caused by anthropogenic activities (e.g., fossil fuel emissions, land use change, and aerosol production) can lead to fundamental changes in global and regional precipitation regimes (e.g., Ramanathan et al. 2001; Vidal and Wade 2008). Both experimental and modeling studies have found that changes in precipitation regimes may profoundly alter ecosystem structure and function (Hely et al. 2006; Knapp et al. 2008; Zeglin et al. 2013; Polade et al. 2014). The simple, quantitative, and physiologically-linked approaches first reported in this study may facilitate predictive understanding of ecological impacts of precipitation regimes in a changing climate. For 
example, climate models predict that the central US will experience more heavy but less moderate precipitation events as the climate warms (Janssen et al. 2014; Cook et al. 2015). If such prediction is borne out, our findings suggest that ecosystems in this region may suffer from increased water stress even if the mean precipitation rate increases.

This study was enabled by long-term continuous measurements of $\psi_{\text {pd }}$. Such datasets are not commonly available at other sites even though they are valuable for studying ecological impacts of precipitation regimes. Since PVI and ARIEP are highly correlated with PLWPI, the temporal integration of $\psi_{\mathrm{pd}}$, they can be applied in place of the latter when only community-level responses are of interest. Gu et al. (2015) already demonstrated the considerable predictive power of PVI and ARIEP for interannual variations in tree mortality. Close relationships of these indices with ecosystem carbon and water fluxes can also be expected. Of course, long-term continuous measurements of $\psi_{\mathrm{pd}}$ are essential for ascertaining species-level responses to precipitation regimes.

\section{Conclusion}

Plant water stress in natural conditions is affected by not only precipitation quantity but also precipitation variability (PV). PV is determined by the distribution of precipitation intensities among the precipitation events (intensity distribution) and by the spacing of precipitation events along the time axis (event spacing). The Precipitation Variability Index (PVI) and the Average Recurrence Interval of Effective Precipitation (ARIEP) integrate the intensity distribution and event spacing aspects of PV for plant water relations. These two indices are closely correlated with temporal integrals of positive 
temperature anomalies and water vapor pressure deficit, two important environmental variables for plant physiology in the context of climate change. Compared with the mean precipitation rate, they can better explain inter-annual variations in the predawn leaf water potential integral (PLWPI) for all species investigated in this study and more effectively differentiate their water stress sensitivities to variations in precipitation regimes. Their application reveals the tradeoffs in species' responses to low and high precipitation variability and suggests that differential sensitivity responses to PV could be part of species-specific water use strategies in a plant community under fluctuating precipitation regimes.

Our study emphasizes that precipitation variability and precipitation amount are both important for plant and community functions and demonstrates the potential of PVI and ARIEP as key indices to study physiological drought and to quantify the ecological and physiological impacts of precipitation regimes on plant communities. They make it possible to assess the projected climate change - related shifts in precipitation regimes in a way that is most relevant to plant physiological and metabolic functions. They also provide simple approaches to testing predictive capabilities of climate models for precipitation regimes.

\section{Acknowledgments}

We thank Drs. Ankur Desai, Paul Hanson, Jason Hubbart, Daria Kluver, Todd Scanlon, Jeffery Warren and Stan Wullschleger for suggestions to improve the paper. This material is based upon work supported by the U.S. Department of Energy, Office of 
Science, Office of Biological and Environmental Research Program, Climate and Environmental Sciences Division. Oak Ridge National Laboratory (ORNL) is managed by University of Tennessee (UT)-Battelle, LLC, for the U.S. Department of Energy under contract DE-AC05-00OR22725. U.S. Department of Energy support for the University of Missouri (Grant DE-FG02-03ER63683) is gratefully acknowledged.

\section{References}

Albertson FW, Weaver JE. 1945. Injury and death or recovery of trees in prairie climate. Ecological Monographs 15: 393-433.

Anderson DR. 2010. Modeled Based Inference in the Life Sciences: A Primer on Evidence. Springer, New Yorker, 184 pages.

Aranda I, Gil L, Pardos JA. 2004. Improvement of growth conditions and gas exchange of Fagus sylvatica L. Seedlings planted below a recently thinned Pinus sylvestris L. Stand. Trees - Structure and Function 18: 211-220.

Bahari ZA, Pallardy SG, Parker WC. 1985. Photosynthesis, water relations and drought adaptation in six woody species of oak-hickory forests in central Missouri. For. Sci. 31: 557-69.

Baldocchi DD, Ryu Y. 2011. A synthesis of forest evaporation fluxes-from days to yearsas measured with eddy covariance. In: Forest Hydrology and Biogeochemistry: Synthesis of Past Research and Future Directions (eds Lavia D, Carlyle-Moses 
D), pp101-116. Ecological Studies 216, Springer. DOI 10.1007/978-94-007-1363$5 \_5$.

Beis A, Patakas A. 2010. Differences in stomatal responses and root to shoot signalling between two grapevine varieties subjected to drought. Funct. Plant Biol. 37: 13946.

Belden AC, Pallardy SG. 2009. Successional trends and apparent Acer saccharum regeneration failure in an oakhickory forest in central Missouri, USA. Plant Ecology 204: 305-322.

Bonnin GM, Martin D, Lin B, Parzybok T, Yekta M, Riley D (2006) PrecipitationFrequency Atlas of the United States. NOAA Atlas 14, Vol. 2, Version 3.

Breshears DD, Myers OB, Meyers CW, Barnes FJ, Zou CB, Allen CD, McDowell NG, Pockman WT. 2009. Tree die-off in response to global change-type drought: Mortality insights from a decade of plant water potential measurements. Frontiers in Ecology and Environment 7: 185-189.

Bronikowski A, Webb C. 1996. Appendix: a critical examination of rainfall variability measures used in behavioral ecology studies. Behav. Ecol. Sociobiol. 39: 27-30.

Chang M. 2012. Forest Hydrology: An Introduction to Water and Forests. $3^{\text {rd }}$ Edition. CRC Press. Boca Raton, Florida. 569 pages.

Cook BI, Ault TR, Smerdon JE. 2015. Unprecedented 21st century drought risk in the American Southwest and Central Plains. Science Advances, 1, DOI: 10.1126/sciadv. 1400082 . 
Craine JM, Nippert JB, Elmore AJ, Skibbe AM, Hutchinson SL, Brunsell NA. 2012.

Timing of climate variability and grassland productivity. PNAS 109: 3401-3405.

Critchfield HJ.1966. General Climatology. 446 pp., Prentice-Hall, Upper Saddle River, N. J.

Dai AG. 2011a. Drought under global warming: a review. Wiley Interdisciplinary Reviews: Climate Change 2: 45-65.

Dai AG. 2011b. Characteristics and trends in various forms of the Palmer Drought Severity Index during 1900-2008. Journal of Geophysical ResearchAtmospheres 116, Article Number: D12115, DOI: 10.1029/2010JD015541.

Donovan LA, Grise D, West JB, Pappert R, Alder NN, Richards JH. 1999. Predawn disequilibrium between plant and soil water potentials in two cold-desert shrubs. Oecologia 120: 209-17.

Donovan LA, Linton MJ, Richards JH. 2001. Predawn plant water potential does not necessarily equilibrate with soil water potential under well-watered conditions. Oecologia 129: 328-35.

Fatichi S, Ivanov VY, Caporali E. 2012. Investigating interannual variability of precipitation at the global scale: is there a connection with seasonality? J. Climate 25: 5512-5523.

Giordano PA, Hibbs DE. 1993. Morphological response to competition in red alder: The role of water. Funct. Ecol. 7: 462-468. 
Gouvra E, Grammatikopoulos G. 2007. Diurnal and seasonal trends of water relations in five co-occurring chasmophytic species. Flora 202: 237-248.

Griffiths H, Parry MAJ. 2002. Plant responses to water stress. Annals of Botany 89: 801802.

Groisman PY, Knight RW, Karl TR. 2012. Changes in intense precipitation over the central United States. J. Hydrometeor. 13: 47-66.

Gu L, Meyers T, Pallardy SG, Hanson PJ, Yang B, Heuer M, Hosman KP, Liu Q, Riggs JS, Sluss D, Wullschleger SD. 2007. Influences of biomass heat and biochemical energy storages on the land surface fluxes and radiative temperature. Journal of Geophysical Research-Atmosphere 112, D02107, doi:10.1029/2006JD007425.

Gu L, Meyers T, Pallardy SG, Hanson PJ, Yang B, Heuer M, Hosman KP, Riggs JS, Sluss D, Wullschleger SD. 2006. Direct and indirect effects of atmospheric conditions and soil moisture on surface energy partitioning revealed by a prolonged drought at a temperate forest site. Journal of Geophysical Research Atmosphere 111, D16102, doi:10.1029/2006JD007161.

Gu L, Pallardy SG, Tu K, Law BE, Wullschleger SD. 2010. Reliable estimation of biochemical parameters from $\mathrm{C}_{3}$ leaf photosynthesis-intercellular carbon dioxide response curves. Plant, Cell and Environment 33: 1852-1874.

Gu L, Pallardy SG, Hosman KP, Y Sun. 2015. Drought-influenced mortality of tree species with different predawn leaf water dynamics in a decade-long study of a central US forest. Biogeosciences 12: 2831-2845. 
Hanson PJ, Todd DE, Huston MA. 2003 Walker Branch throughfall displacement experiment (TDE). In: North American Temperate Deciduous Forest Responses to Changing Precipitation Regimes (eds Hanson PJ, Wullschleger SD), pp. 8-31. Ecological Studies 166, Springer, New York.

Harper CW, Blair JM, Fay PA, Knapp AK, Carlisle JD. 2005. Increased rainfall variability and reduced rainfall amount decreases soil $\mathrm{CO} 2$ flux in a grassland ecosystem. Global Change Biology 11: 322-334.

Heim RR. 2002. A review of twentieth-century drought indices used in the United States. Bulletin of the American Meteorological Society 83: 1149-1165.

Hely C, Bremond L, Alleaume S, Smith B, Sykes MT, Guiot J. 2006. Sensitivity of African biomes to changes in the precipitation regime. Global Ecology and Biogeography 15: 258-270.

Heisler-White JL, Blair JM, Kelly EF, Harmoney K, Knapp AK. 2009 Contingent productivity responses to more extreme rainfall regimes across a grassland biome. Global Change Biology 15: 2894-2904.

Helvey JD, Patri JH. 1965. Canopy and litter interception of rainfall by hardwoods of eastern United States. Water Resources Research 1: 193-206.

Hsiao TC. 1973. Plant responses to water stress. Annu. Rev. Plant Physiol. 24: 519- 570.

Janssen E, Wuebbles DJ, Kunkel KE, Olsen SC, Goodman A. 2014. Observational- and model-based trends and projections of extreme precipitation over the contiguous United States. Earth's Future 2: 99-113. 
Jenkins M, Pallardy SG. 1995. The influence of drought on red oak group species growth and mortality in the Missouri Ozarks. Canadian Journal of Forest Research 25: $1119-1127$.

Kavanagh KL, Pangle R, Schotzko AD. 2007. Nocturnal transpiration causing disequilibrium between soil and stem predawn water potential in mixed conifer forests of Idaho. Tree Physiology: 27, 621-629.

Klepper B. 1968. Diurnal pattern of water potential in woody plants. Plant Physiology 43: 1931-1934.

Knapp AK, Beier C, Briske DD, Classen AT, Luo YQ, Reichstein M, Smith MD, Smith SD, Bell JE, Fay PA, Heisler JL, Leavitt SW, Sherry R, Smith B, Weng ES. 2008. Consequences of more extreme precipitation regimes for terrestrial ecosystems. BioScience 58: 1-11.

Laio F, Porporato A, RidolfiL, Rodriguez-Iturbe I. 2001. Plants in water-controlled ecosystems: active role in hydrologic processes and response to water stress-II. Probabilistic soil moisture dynamics. Adv. Water Resour. 24:707-723.

Lambers H, Chapin III FS, Pons TL. 2008. Plant Physiological Ecology, $2^{\text {nd }}$ Edition. 605p. Springer, New York.

Loewenstein NJ, Pallardy SG. 1998. Drought tolerance, xylem sap abscisic acid and stomatal conductance during soil drying: A comparison of canopy trees of three temperate deciduous angiosperms. Tree Physiol.: 18, 431-40. 
Martínez-Vilalta J, Poyatos R, Aguadé D, Retana J, Mencuccini M. 2014. A new look at water transport regulation in plants. New Phytologist 204: 105-115.

McDowell NG, Pockman W, Allen C, Breshears D, Cobb N, Kolb T, Plaut J, Sperry J, West A, Williams D et al. 2008. Mechanisms of plant survival and mortality during drought: why do some plants survive while others succumb? New Phytologist 178: 719-739.

McDowell NG, Sevanto S. 2010. The mechanisms of carbon starvation: how, when, or does it even occur at all? New Phytologist 186: 264-266.

McDowell NG. 2011. Mechanisms linking drought, hydraulics, carbon metabolism, and vegetation mortality. Plant Physiology 155: 1051-1059.

McDowell NG, Beerling DJ, Breshears DD, Fisher RA, Raffa KF, Stitt M. 2011. The interdependence of mechanisms underlying climate-driven vegetation mortality. Trends in Ecology and Evolution 26: 523-532.

Meehl GA, Tebaldi C. 2004. More intense, more frequent, and longer lasting heat waves in the 21st century. Science 305: 994-997.

Mitchell PJ, O'grady AP, Tissue DT, White DA, Ottenschlaeger ML, Pinkard EA. 2013. Drought response strategies define the relative contributions of hydraulic dysfunction and carbohydrate depletion during tree mortality. New Phytologist 197: 862-72.

Monti A, Venturi G. 2007. A simple method to improve the estimation of the relationship between rainfall and crop yield. Agron. Sustain. Dev. 27: 255-260. 
Myers BJ. 1988. Water stress integral-a link between short-term stress and long-term growth. Tree Physiology 4: 315-323.

Noy-Meir I. 1973. Desert ecosystems: environment and producers. Ann. Rev. Ecol. Systemat. 4: 25-51.

Orlowsky B, Seneviratne SI. 2013. Elusive drought: uncertainty in observed trends and short- and long-term CMIP5 projections. Hydrol. Earth Syst. Sci. 17: 1765-1781.

Pallardy SG, Pereira JS, Parker WC. 1991. Measuring the state of water in tree systems. In: Techniques and Approaches in Forest Tree Ecophysiology. (Eds. Lassoie JP, Hinckley TM), pp. 28-76, CRC Press, Boca Raton, FL.

Pallardy SG, Nigh TA, Garrett HE. 1988. Changes in forest composition in central Missouri: 1968-1982. Am. Midland Nat. 120: 380-390.

Pallardy SG. 2008. Physiology of Woody Plants. $3^{\text {rd }}$ Edition, Academic Press, Burlington, MA.

Pallardy SG, Gu L, Hosman KP, Sun, Y. 2015. Predawn Leaf Water Potential of OakHickory Forest at Missouri Ozark (MOFLUX) Site: 2004-2014. Carbon Dioxide Information Analysis Center, Oak Ridge National Laboratory, U.S. Department of Energy, Oak Ridge, Tennessee, U.S.A. http://dx.doi.org/10.3334/CDIAC/ornlsfa.004

Pereira JS, Tenhunen JD, Lange OL, Beyschlag W, Meyer A, David MM. 1986. Seasonal and diurnal patterns in leaf gas exchange of Eucalyptus globulus trees growing in Portugal. Can. J. For. Res. 16: 177-184. 
Perry MA, Mitchell RJ, Zutter BR, Glover GR, Gjerstad DH. 1994. Seasonal variation in competitive effect on water stress and pine responses. Can. J. For. Res. 24: 14401449.

Polade SD, Pierce DW, Cayan DR, Gershunov A, Dettinger MD. 2014. The key role of dry days in changing regional climate and precipitation regimes. Scientific Reports 4: Article Number 4364, DOI: 10.1038/srep04364.

Porporato A, D'Odorico P, Laio F, Ridolfi L, Rodriguez-Iturbe I. 2002. Ecohydrology of water-controlled ecosystems. Advances in Water Resources 25: 1335-1348.

Porporato A, Laio F, RidolfiL, Rodriguez-Iturbe I. 2001. Plants in water-controlled ecosystems: active role in hydrologic processes and response to water stress - III. Vegetation water stress. Adv. Water Resour. 24:725-744.

Ramanathan V, Crutzen PJ, Kieh JT, Rosenfeld D. 2001. Aerosols, climate, and the hydrological cycle. Science 294: 2119-2124.

Rice KJ, Matzner SL, Byer W, Brown JR. 2004. Patterns of tree dieback in Queensland, Australia: The importance of drought stress and the role of resistance to cavitation. Oecologia 139: 190-198.

Rigby JR, Porporato A. 2010. Precipitation, dynamic intermittency, and sporadic randomness. Advances in Water Resources 33: 923-932.

Rochow JJ. 1972. A vegetational description of a mid-Missouri forest using gradient analysis techniques. Am. Midland Nat. 87: 377-396. 
Running SW. 1976. Environmental control of leaf water conductance in conifers. Can. J. For. Res. 6: 104-112.

Schlesinger RC. 1990. White ash. In: Silvics of North America, Vol 2. Hardwoods. (Burns RM, Honkala BH, tech. coords.) U.S. Department of Agriculture, Forest Service, Agriculture Handbook 654. Washington, DC. 877 p.

Schulze ED, Lange OL, Evenari M, Kappen L, Buschbom U. 1980. Long-term effects of drought on wild and cultivated plants of the Negev desert I. Maximal rates of net photosynthesis. Oecologia 45: 11-18.

Sevanto S, McDowell NG, Dickman LT, Pangle R, Pockman WT. 2014. How do trees die? A test of the hydraulic failure and carbon starvation hypotheses. Plant Cell and Environment 37: 153-161.

Sun Y, Gu L, Dickinson RE, Pallardy SG, Baker J, Cao Y, DaMatta FM, Dong X, Ellsworth D, Goethem DV, Jensen AM, Law BE, Loos R, Martins SCV, Norby RJ, Warren J, Weston D, Winter K. 2014. Asymmetrical effects of mesophyll conductance on fundamental photosynthetic parameters and their relationships estimated from leaf gas exchange measurements. Plant Cell and Environment 37: 978-994.

Tang AC, Boyer JS. 2002. Growth-induced water potentials and the growth of maize leaves. J. Exp. Bot. 53: 489-503.

Thomas DS, Eamus D. 1999. The influence of predawn leaf water potential on stomatal responses to atmospheric water content at constant $C_{i}$ and on stem hydraulic 
conductance and foliar ABA concentrations. Journal of Experimental Botany 50: 243-251.

Trenberth KE, Dai AG, van der Schrier G, Jones PD, Barichivich J, Briffa KR, Sheffield J. 2014. Global warming and changes in drought. Nature - Climate Change 4: 1722.

Tyree MT. 1988. A dynamic-model for water-flow in a single tree - evidence that models must account for hydraulic architecture. Tree Physiology 4: 195-217.

Turner NC. 1981. Correction of flow resistances of plants measured from covered and exposed leaves. Plant Physiology 68: 1090-1092.

Van Dijk AIJM, Bruijnzeel LA. 2001. Modelling rainfall interception by vegetation of variable density using an adapted analytical model. Part 1. Model description. Journal of Hydrology 27: 230-238.

Vidal JP, Wade SD. 2008. Multimodel projections of catchment-scale precipitation regime. Journal of Hydrology 353: 143-158.

Villarini G, Smith JA, Vecchi GA. 2013. Changing frequency of heavy rainfall over the central United States. J. Climate 26: 351-357.

Vose, James M.; Peterson, David L.; Patel-Weynand, Toral, eds. 2012. Effects of climatic variability and change on forest ecosystems: a comprehensive science synthesis for the U.S. forest sector. Gen. Tech. Rep. PNW-GTR-870. Portland, OR: U.S. Department of Agriculture, Forest Service, Pacific Northwest Research Station. $265 \mathrm{p}$. 
White DA, Crombie DS, Kinal J, Battaglia M, McGrath JF, Mendhama DS, Walker SN. 2009. Managing productivity and drought risk in Eucalyptus globulus plantations in south-western Australia. Forest Ecology and Management 259: 33-44.

Wu CY, Chen JM, Desai AR, Lafleur PM, Verma SB. 2013. Positive impacts of precipitation intensity on monthly $\mathrm{CO}_{2}$ fluxes in North America. Global and Planetary Change 100: 204-214.

Yang B, Pallardy SG, Meyers TP, Gu LH, Hanson PJ, Wullschleger SD, Heuer M, Hosman KP, Riggs JS, Sluss DW. 2010. Environmental controls on water use efficiency during severe drought in an Ozark Forest in Missouri, USA. Global Change Biology 16: 2252-2271.

Yang Y, Timlin D, Fleisher D, Kim S-H, Quebedeaux B, Reddy V. 2009. Simulating leaf area of corn plants at contrasting water status. Agricultural and Forest Meteorology 149: 1161-1167.

Young FJ, Radatz CA, Marshall CA. 2001. Soil Survey of Boone County, Missouri. United States Department of Agriculture, Natural Resources Conservation Service.

Zargar A, Sadiq R, Naser B, Khan, FI. 2011. A review of drought indices. Environmental Reviews 19: 333-349.

Zeglin LH, Bottomley PJ, Jumpponen A, Rice CW, Arango M, Lindsley A, McGowan A, Mfombep P, Myrold DD. 2013. Altered precipitation regime affects the function 
and composition of soil microbial communities on multiple time scales. Ecology

94: 2334-2345. 
Table 1. Empirical parameters estimated from fitting Eqs .12-14 to measurements of predawn leaf water potential integral (PLWPI) and values of the mean daily precipitation rate $(\bar{p})$, Precipitation Variability Index (PVI), and Average Recurrence Interval of Effective Precipitation with the threshold $p_{t}=5 \mathrm{~mm} \mathrm{day}^{-1}$ (ARIEP5). The values in the second sub-row of each main row for PVI fitting do not include 2006 in the analysis. RMSE stands for root mean square error.

\begin{tabular}{|c|c|c|c|c|c|c|c|c|c|c|c|c|}
\hline \multirow[t]{2}{*}{ Species } & \multicolumn{3}{|c|}{ Parameters in $\bar{p}$ fitting } & \multicolumn{4}{|c|}{ Parameters in PVI fitting } & \multicolumn{5}{|c|}{ Parameters in ARIEP5 fitting } \\
\hline & $a$ & $b$ & RMSE & $c$ & $d$ & $e$ & RMSE & $f$ & $g$ & $h$ & $k$ & RMSE \\
\hline \multirow[t]{2}{*}{ White oak } & \multirow[t]{2}{*}{32.91} & \multirow[t]{2}{*}{327.73} & \multirow[t]{2}{*}{24.6} & -392.64 & 355.21 & 0.51 & 19.5 & \multirow[t]{2}{*}{-49.68} & \multirow[t]{2}{*}{-209.78} & \multirow[t]{2}{*}{2.69} & \multirow[t]{2}{*}{17.37} & \multirow[t]{2}{*}{10.5} \\
\hline & & & & -325.87 & 307.92 & 0.76 & 7.64 & & & & & \\
\hline \multirow[t]{2}{*}{ Black oak } & \multirow[t]{2}{*}{43.57} & \multirow[t]{2}{*}{379.66} & \multirow[t]{2}{*}{27.5} & -257.50 & 261.70 & 1.80 & 27.5 & \multirow[t]{2}{*}{-49.39} & \multirow[t]{2}{*}{-197.19} & \multirow[t]{2}{*}{1.68} & \multirow[t]{2}{*}{52.07} & \multirow[t]{2}{*}{14.3} \\
\hline & & & & -255.44 & 291.44 & 2.00 & 7.71 & & & & & \\
\hline \multirow[t]{2}{*}{ Sugar maple } & \multirow[t]{2}{*}{17.15} & \multirow[t]{2}{*}{348.79} & \multirow[t]{2}{*}{24.8} & -249.20 & 225.27 & 1.86 & 34.3 & \multirow[t]{2}{*}{-62.50} & \multirow[t]{2}{*}{-176.85} & \multirow[t]{2}{*}{1.40} & \multirow[t]{2}{*}{88.38} & \multirow[t]{2}{*}{7.6} \\
\hline & & & & -247.53 & 263.34 & 2.13 & 9.88 & & & & & \\
\hline \multirow[t]{2}{*}{ White ash } & \multirow[t]{2}{*}{9.54} & \multirow[t]{2}{*}{467.24} & \multirow[t]{2}{*}{34.1} & -309.22 & 336.27 & 3.38 & 49.0 & -84.02 & -225.95 & 1.20 & 119.57 & 16.5 \\
\hline & & & & -313.18 & 394.74 & 3.39 & 17.4 & & & & & \\
\hline Eastern & -12.74 & 325.83 & 22.0 & -288.90 & 227.95 & 1.37 & 26.2 & -93.56 & -175.62 & 1.81 & 43.11 & 14.2 \\
\hline 1 & & & & -281.88 & 250.51 & 1.64 & 7.7 & & & & & \\
\hline Shagbark & 11.51 & 352.78 & 38.4 & -242.86 & 217.08 & 2.18 & 48.8 & -68.09 & -173.51 & 0.98 & 579.80 & 19.4 \\
\hline & & & & -243.90 & 274.25 & 2.47 & 15.1 & & & & & \\
\hline Community & 19.88 & 356.59 & 22.7 & -266.31 & 237.75 & 1.59 & 30.2 & -65.06 & -186.45 & 1.66 & 51.21 & 10.7 \\
\hline & & & & -261.49 & 268.91 & 1.87 & 5.11 & & & & & \\
\hline
\end{tabular}




\section{Figure captions}

Fig.1. Illustration of calculations of various variability measures for two hypothetical patterns of precipitation events with an identical rate of $10 \mathrm{~mm} \mathrm{day}^{-1}$. The indices are calculated for an evaluation duration of 60 days. (a) Pattern I, rain falls in the first 10 days only. (b) Pattern II, rain occurs every 6 days. (c) cumulative precipitation of Pattern I (dash-dot), Pattern II (dash), and cumulative mean line (solid). The cumulative mean line is the same for Pattern I and II because these two patterns have the same mean precipitation rate for the 60-day period. Values of the Shannon Index (Bronikowski and Webb 1996), Coefficient of Variation (CV), the evenness (U) and weighted evenness (W) index of Monti and Venturi (2007) and the Precipitation Variability Index (PVI) for Pattern I and II are given inside the bottom panel. The cumulative curves of Pattern I and II just happen to be located above the cumulative mean line; depending on particular precipitation patterns, cumulative measurement curves can be located below the cumulative mean line.

Fig. 2. The variations of evenness (U, dash-dot) and weighted evenness (W, dash) index of Monti and Venturi (2007) and the Precipitation Variability Index (PVI, solid) with the length of duration for index evaluation. The rainfall repeats every 6 days at the rate of 10 $\mathrm{mm}$ day $^{-1}$ and is the same as the Pattern II in Fig. 1 (however, in Fig. 1, the indices are calculated for a duration of 60 days).

Fig. 3. Seasonal variations in predawn leaf water potential $\psi_{\text {pd }}$ in three selected years of different drought levels: 2009, a wet year (a); 2006, an intermediate drought year (b); and 2012, an extreme drought year (c). 
Fig. 4. Variations of Predawn Leaf Water Potential Integral (PLWPI) with the mean daily precipitation rate $(\bar{p})$ for white oak (a), white ash (b), black oak (c), eastern redcedar (d), sugar maple (e), and shagbark hickory (f). The circled point is year 2006 which has relatively low PVI and low mean precipitation rate. The fitted lines are Eq. 12 with coefficients given in Table 1.

Fig. 5. Variations of Predawn Leaf Water Potential Integral (PLWPI) with the Precipitation Variability Index (PVI) for white oak (a), white ash (b), black oak (c), eastern redcedar (d), sugar maple (e), and shagbark hickory (f). The circled point is the year 2006 which has relatively low PVI and low mean precipitation rate. The fitted lines are Eq. 13 with (solid) and without (dash) 2006 included. The fitting coefficients are given in Table 1.

Fig. 6. Variations of Predawn Leaf Water Potential Integral (PLWPI) with the Average Recurrence Interval of Effective Precipitation (ARIEP) calculated with an effective precipitation threshold rate of $p_{t}=5 \mathrm{~mm} \mathrm{day}^{-1}$ (ARIEP5) for white oak (a), white ash (b), black oak (c), eastern redcedar (d), sugar maple (e), and shagbark hickory (f). The fitted lines are Eq. 14 with coefficients given in Table 1.

Fig. 7. Variations of Predawn Leaf Water Potential Integral (PLWPI) at the plant community level with mean daily precipitation rate (a), Precipitation Variability Index (PVI) (b) and Average Recurrence Interval of Effective Precipitation (ARIEP) calculated with an effective precipitation threshold rate of $p_{t}=5 \mathrm{~mm} \mathrm{day}^{-1}$ (ARIEP5) (c). The fitted lines in b are Eq. 13 with (solid) and without (dash) 2006 included. The fitted lines in a and c are Eqs. 12 and 14, respectively with 2006 included. 
Fig. 8. Variations of Predawn Leaf Water Potential Integral (PLWPI) at the plant community level with Positive Temperature Anomaly Integral (PTAI) (a) and water Vapor Pressure Deficit Integral (VPDI) (b).

Fig. 9. Variations of Positive Temperature Anomaly Integral (PTAI) (a, c, and e) and water Vapor Pressure Deficit Integral (VPDI) (b, $\mathrm{d}$ and f) with mean daily precipitation rate (a and b), Precipitation Variability Index (PVI) (c and d) and Average Recurrence Interval of Effective Precipitation 5 (ARIEP5) (e and f).

Fig. 10. The fitted lines of Eq. 12 for $\bar{p}$ (a), Eq. 13 for PVI with (b) and without (d) the year 2006, and Eq. 14 for ARIEP5 (c) for white oak (WO), black oak (BO), sugar maple (SM), white ash (WA), eastern redcedar (ER), shagbark hickory (SH) and the community (CO). The lines are the same as those in Figs. 4-7 and are put together for easy comparison.

Fig. 11. The sensitivities of Predawn Leaf Water Potential Integral (PLWPI) to changes in mean daily precipitation rate (a), Precipitation Variability Index (PVI) (b and d), and Average Recurrence Interval of Effective Precipitation 5 (ARIEP5) (c). The sensitivities are the derivatives of PLWPI with respect to the mean daily precipitation rate with Eq. 15, to PVI with Eq. 16 (2006 is either included (a) or excluded (b) in the fitting for the PLWPI-PVI relationships), and to ARIEP5 with Eq. 17. WO, white oak; BO, black oak; SM, sugar maple; WA, white ash; ER, eastern redcedar; SH, shagbark hickory ; CO, and the community. 
Fig. 12. The relationship between the community Predawn Leaf Water Potential Integral (PLWPI) and the evenness index U (a) and weighted evenness index W (b) of Monti and Venturi (2007).

Fig. 13. Variations of Precipitation Variability Index (PVI, a) and Average Recurrence Interval of Effective Precipitation 5 (ARIEP5, b) with mean daily precipitation rate $(\bar{p})$. Both PVI and ARIEP5 are correlated with $\bar{p}$. But the correlation for PVI is mainly due to the two low $\bar{p}$ extremes. Excluding these two low extremes, the correlation between PVI and $\bar{p}$ is weak (the inset in a). In contrast, both low and high $\bar{p}$ values contribute to the ARIEP5 - $\bar{p}$ correlation. 


\section{Figure1}
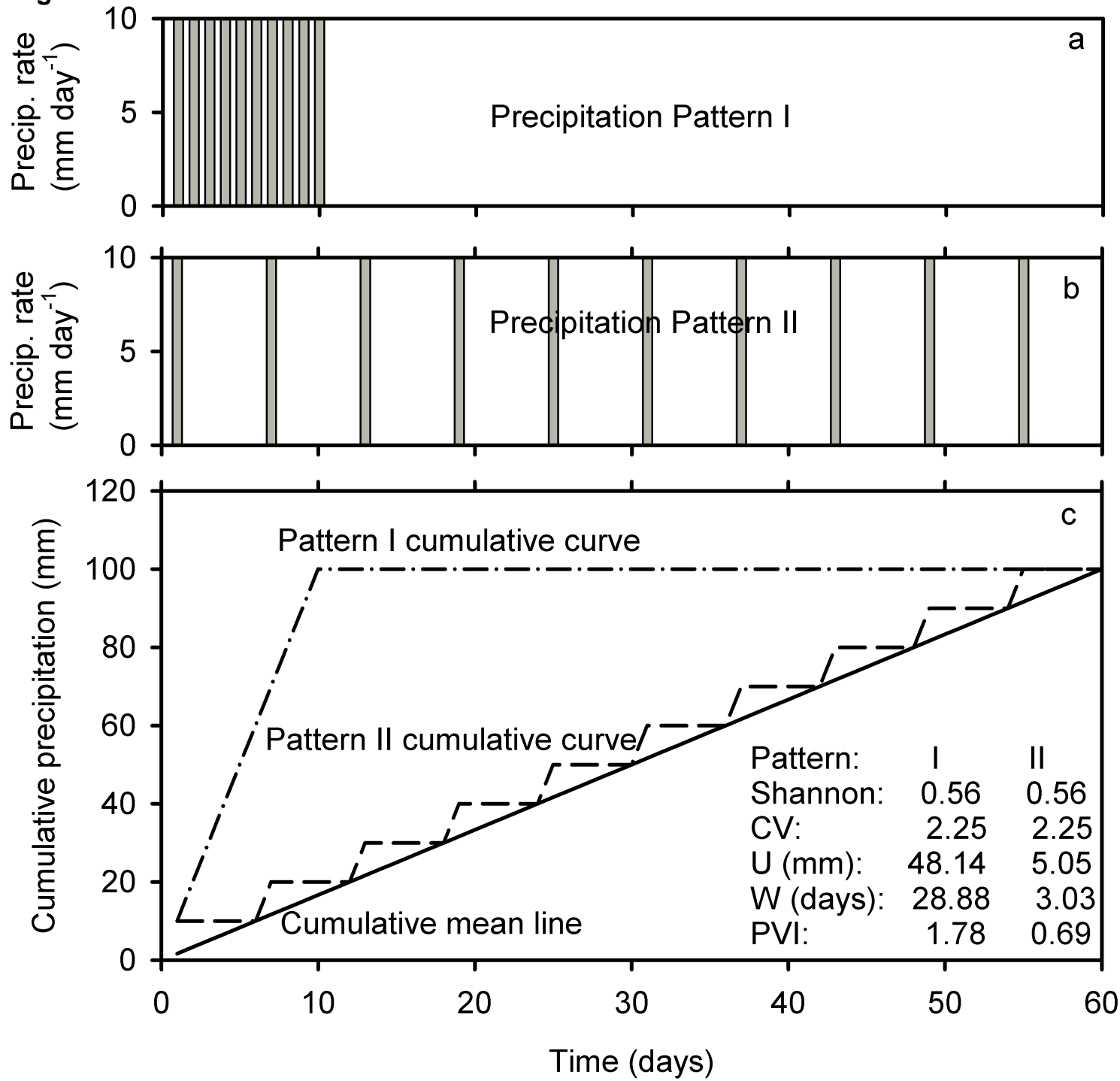


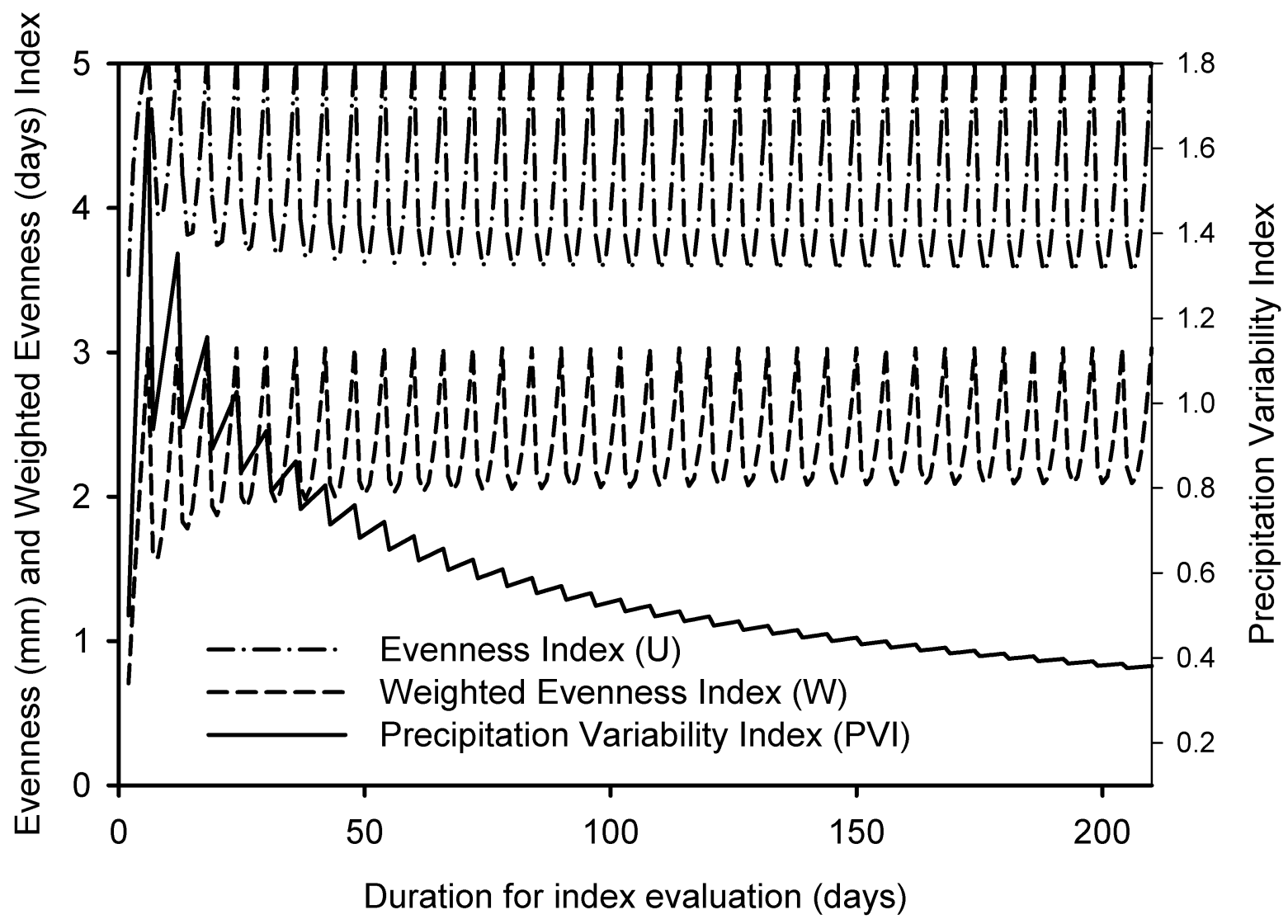



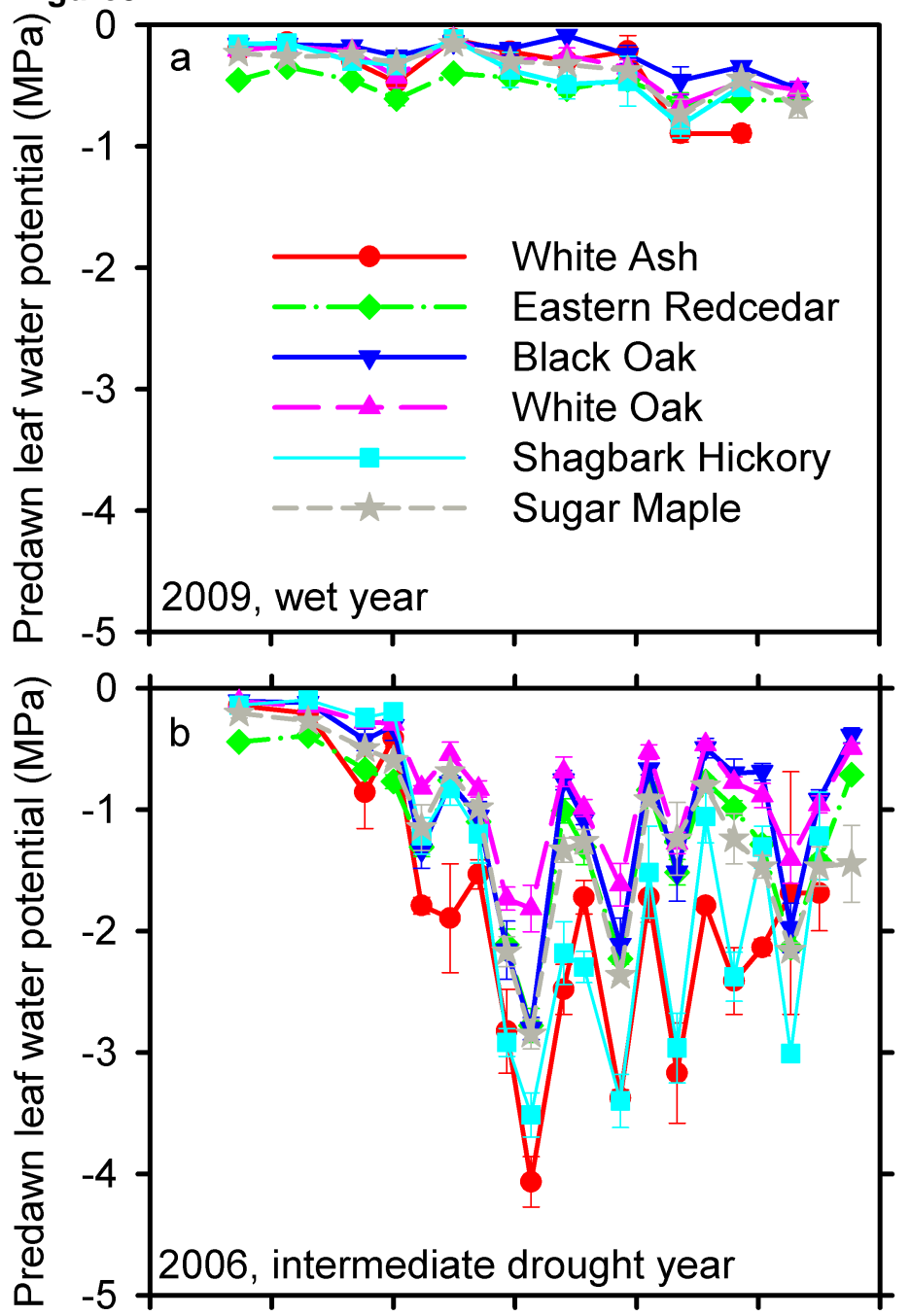

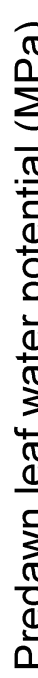

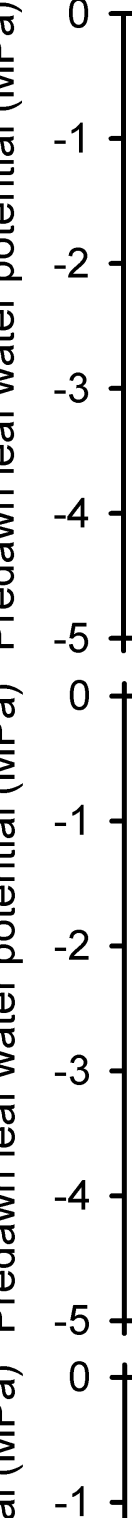
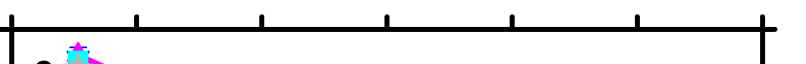

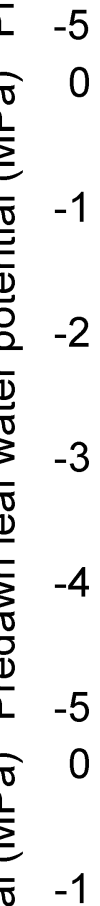

2009, wet year

White Ash

astern

Shagbark Hickory

Sugar Maple

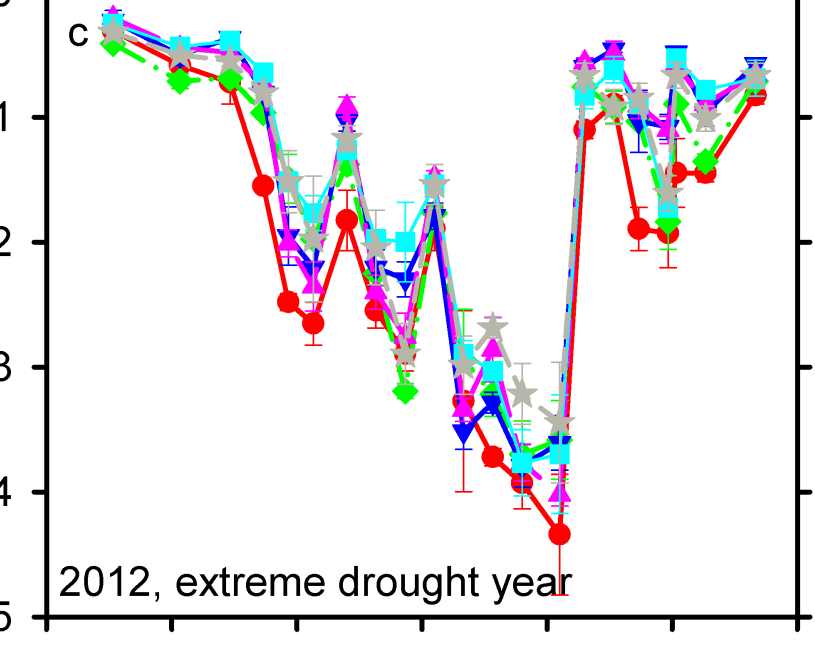

$\begin{array}{lllllll}120 & 150 & 180 & 210 & 240 & 270 & 300\end{array}$

Day of year 
Figure4
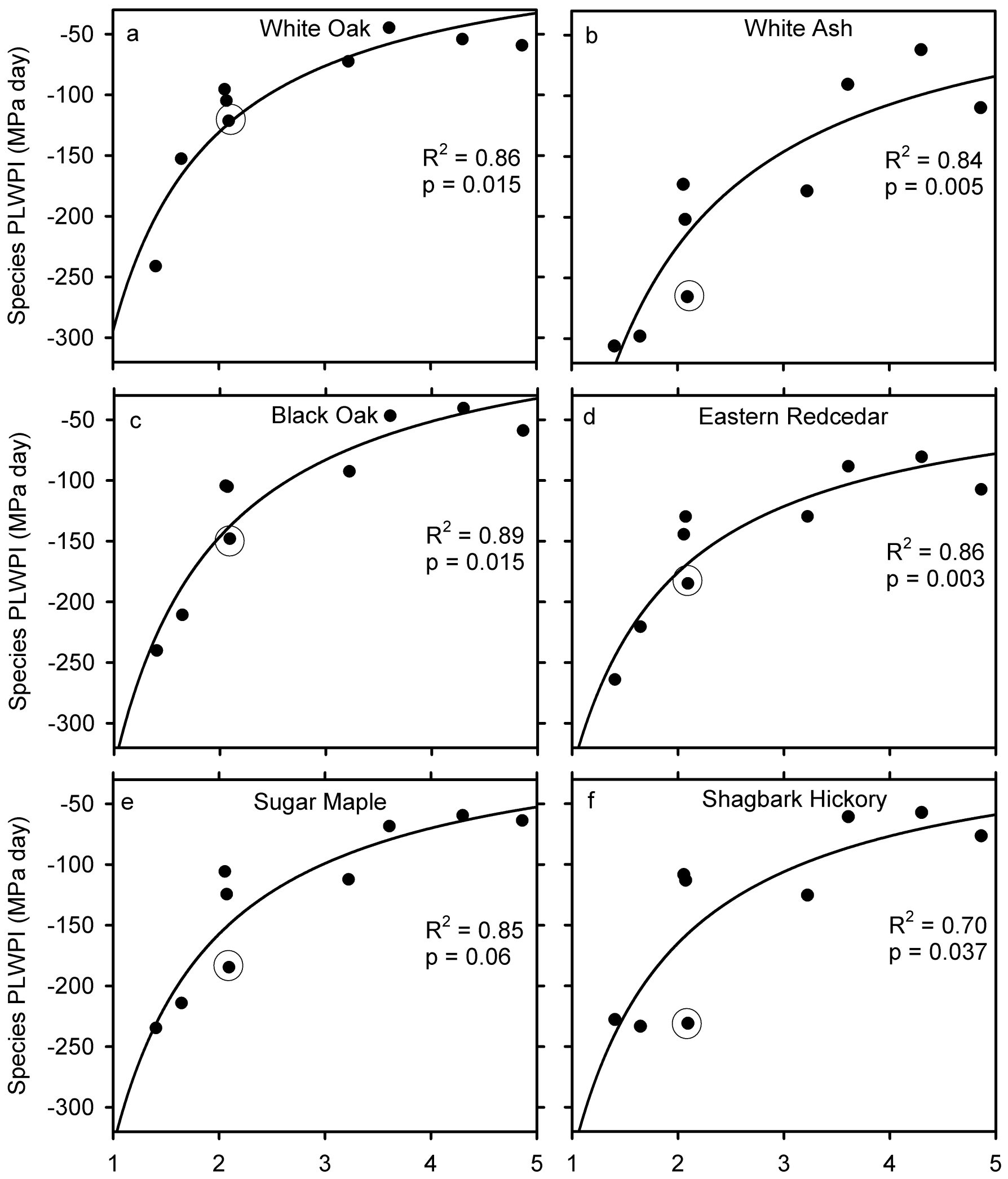

Mean Daily Precipitation Rate $\left(m m\right.$ day $\left.^{-1}\right)$

Mean Daily Precipitation Rate $\left(\mathrm{mm}\right.$ day $\left.^{-1}\right)$ 
Figure7
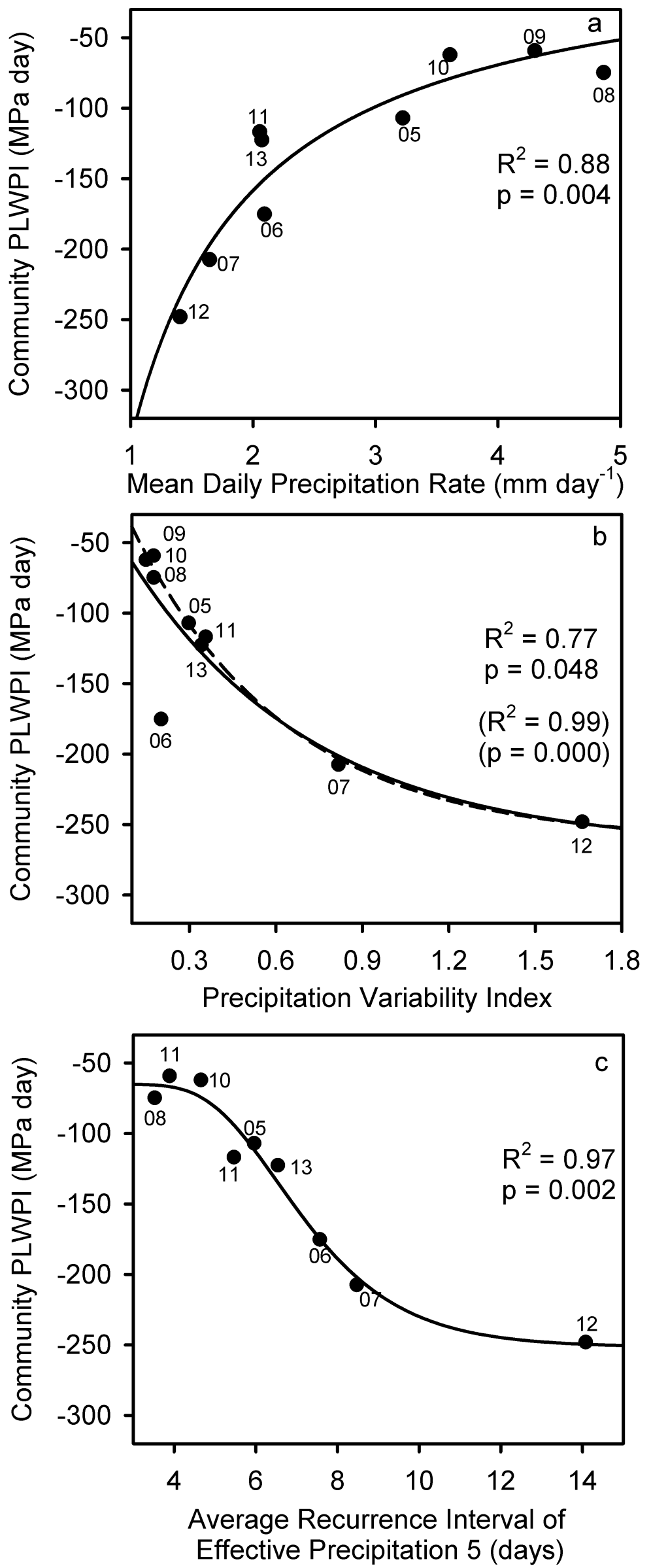


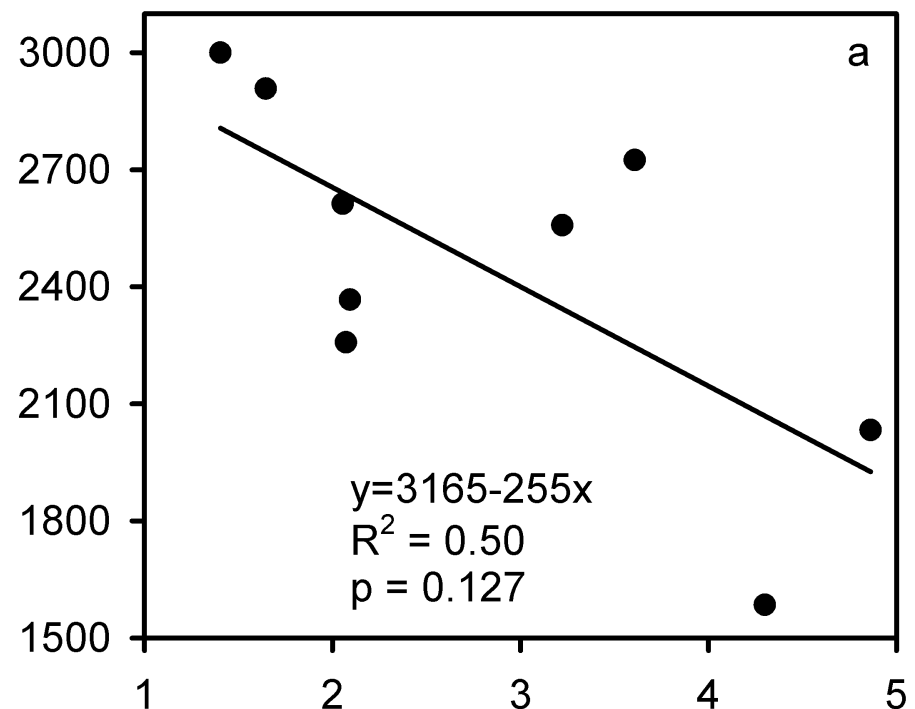

Mean Daily Precip. Rate $\left(\mathrm{mm}\right.$ day $\left.^{-1}\right)$
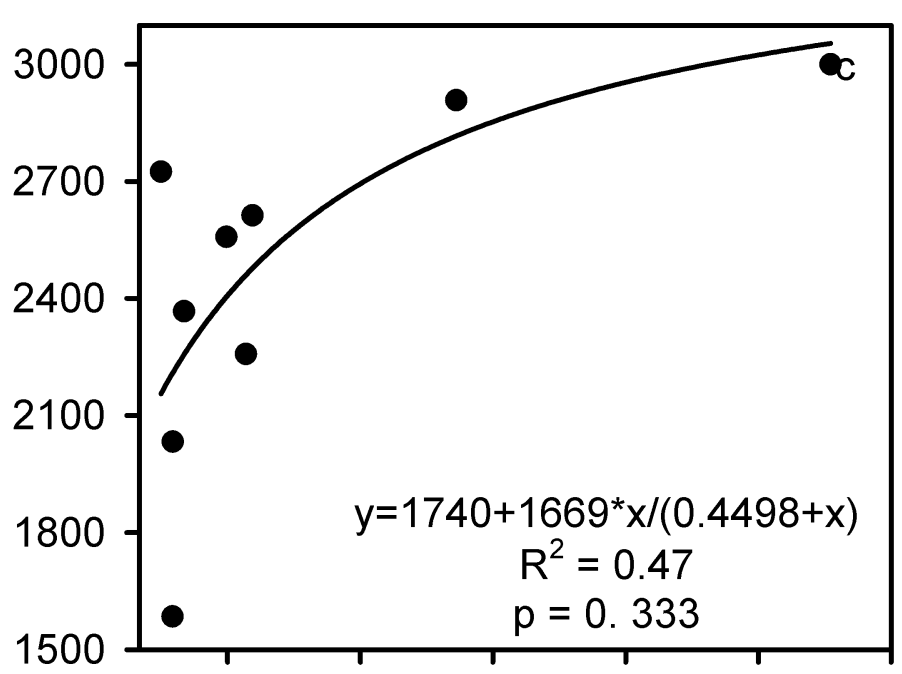

$\begin{array}{llllll}0.3 & 0.6 & 0.9 & 1.2 & 1.5 & 1.8\end{array}$

Precipitation Variability Index

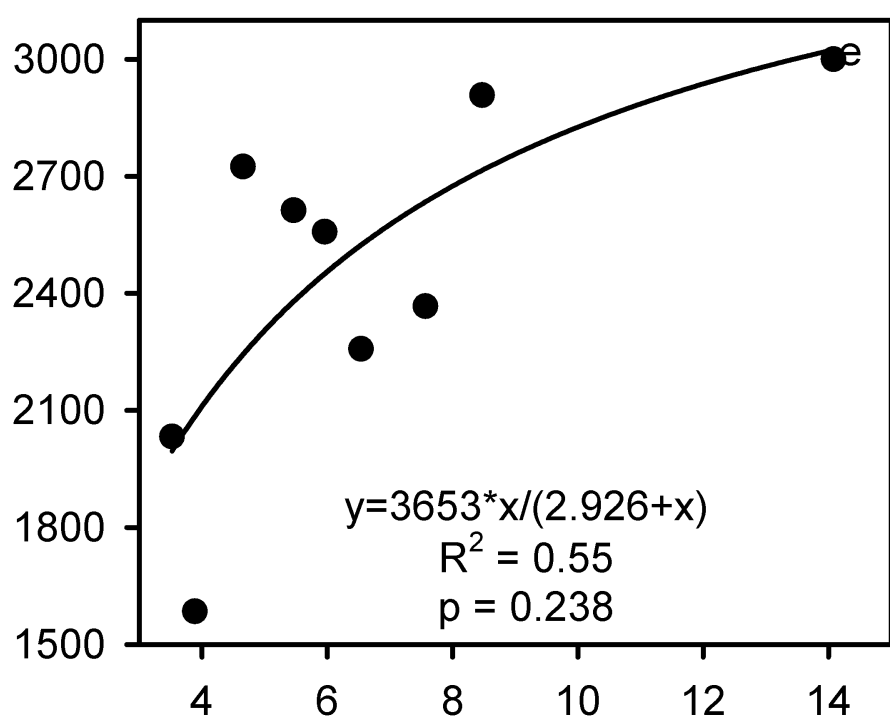

Average Recurrence Interval of Effective Precipitation 5 (days)

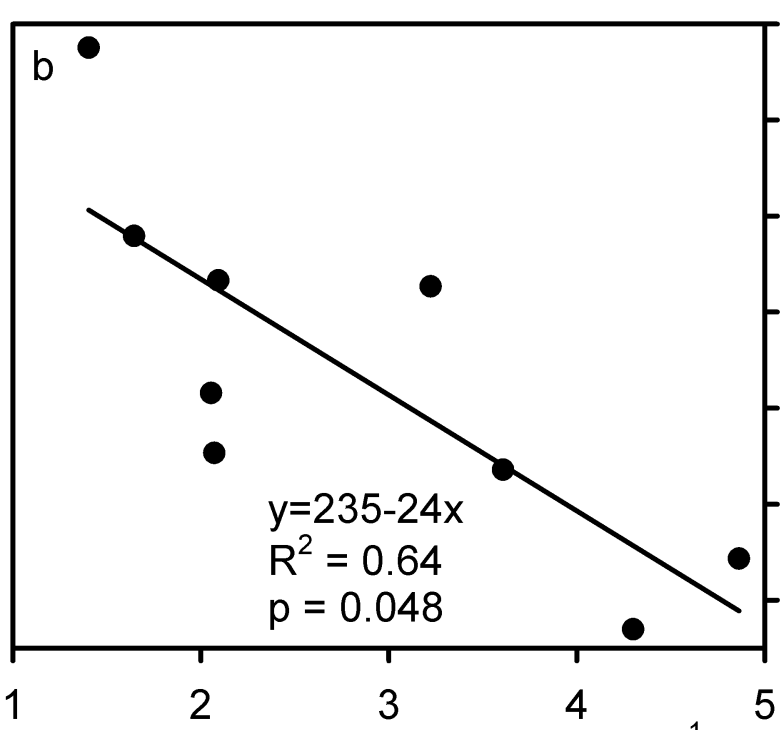

240

Mean Daily Precip. Rate $\left(\mathrm{mm}\right.$ day $\left.^{-1}\right)$

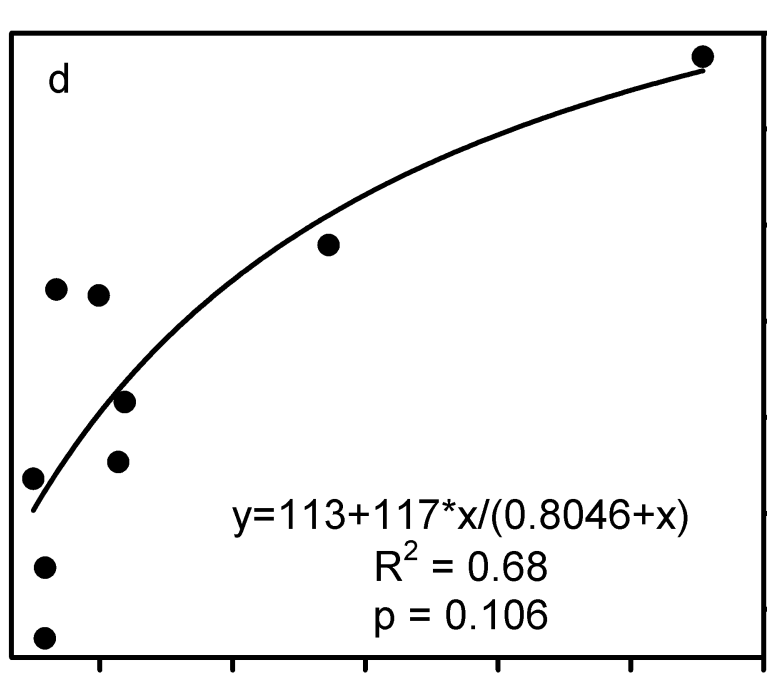

240

220

200

180

160

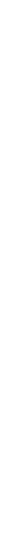

120

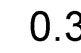

0.6

0.9

1.2

1.5

1.8

Precipitation Variability Index

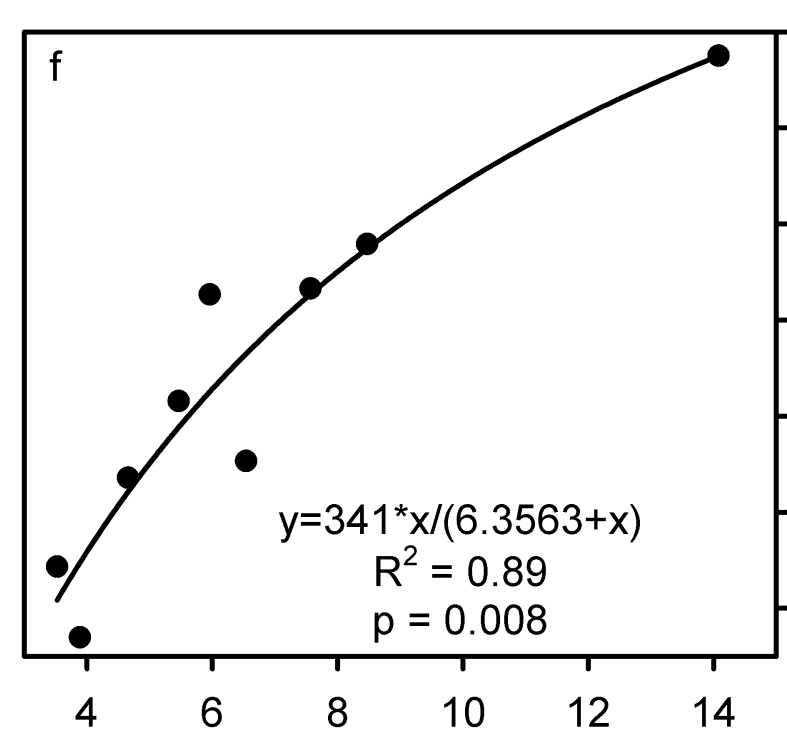

240

220

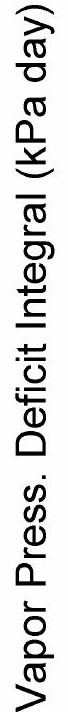

Average Recurrence Interval of Effective Precipitation 5 (days) 

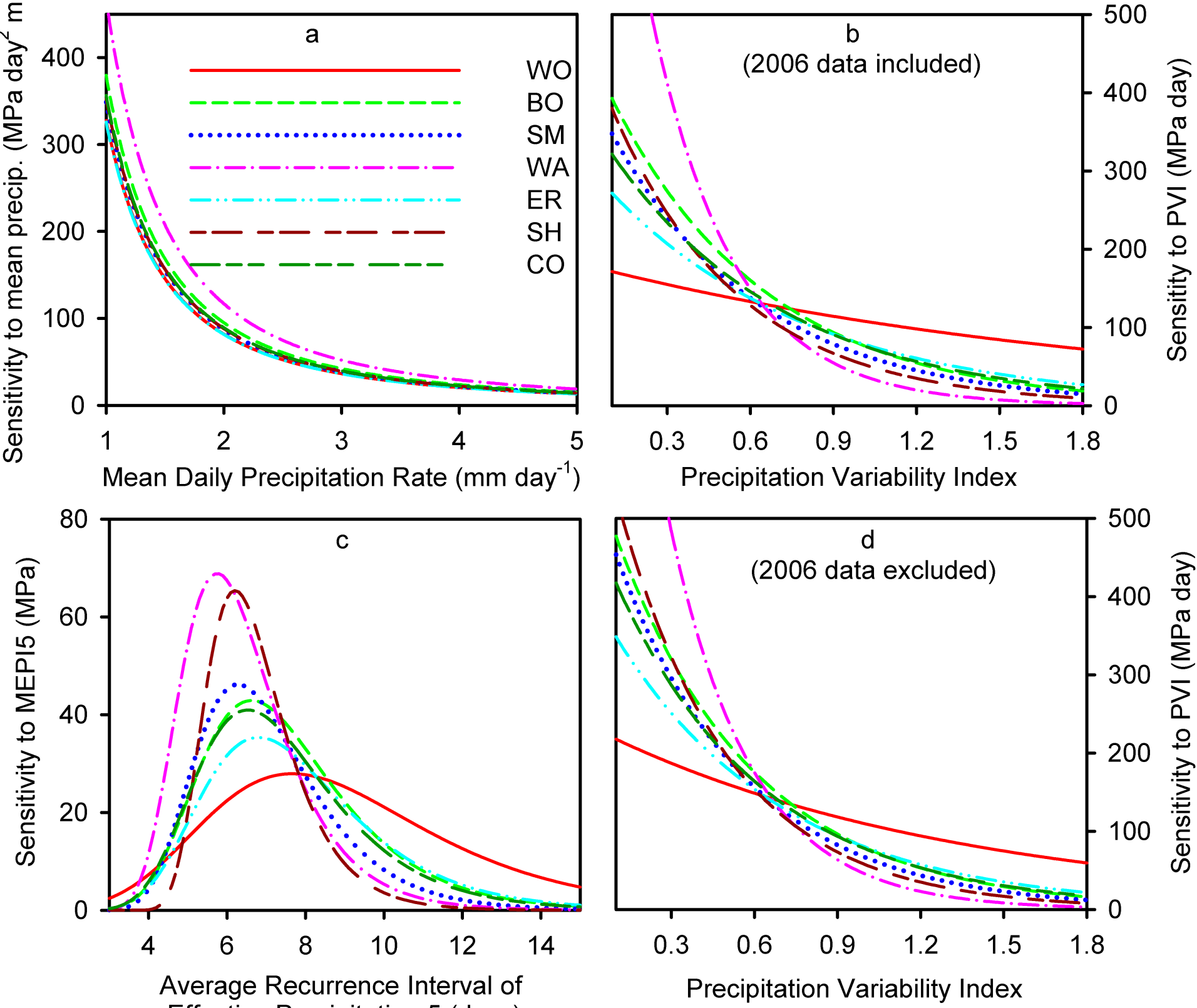

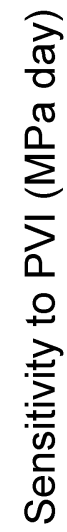

Average Recurrence Interval of Effective Precipitation 5 (days) 
Figure12

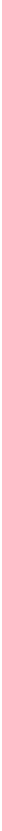

Evenness Index (mm)

Weighted Evenness Index (days) 

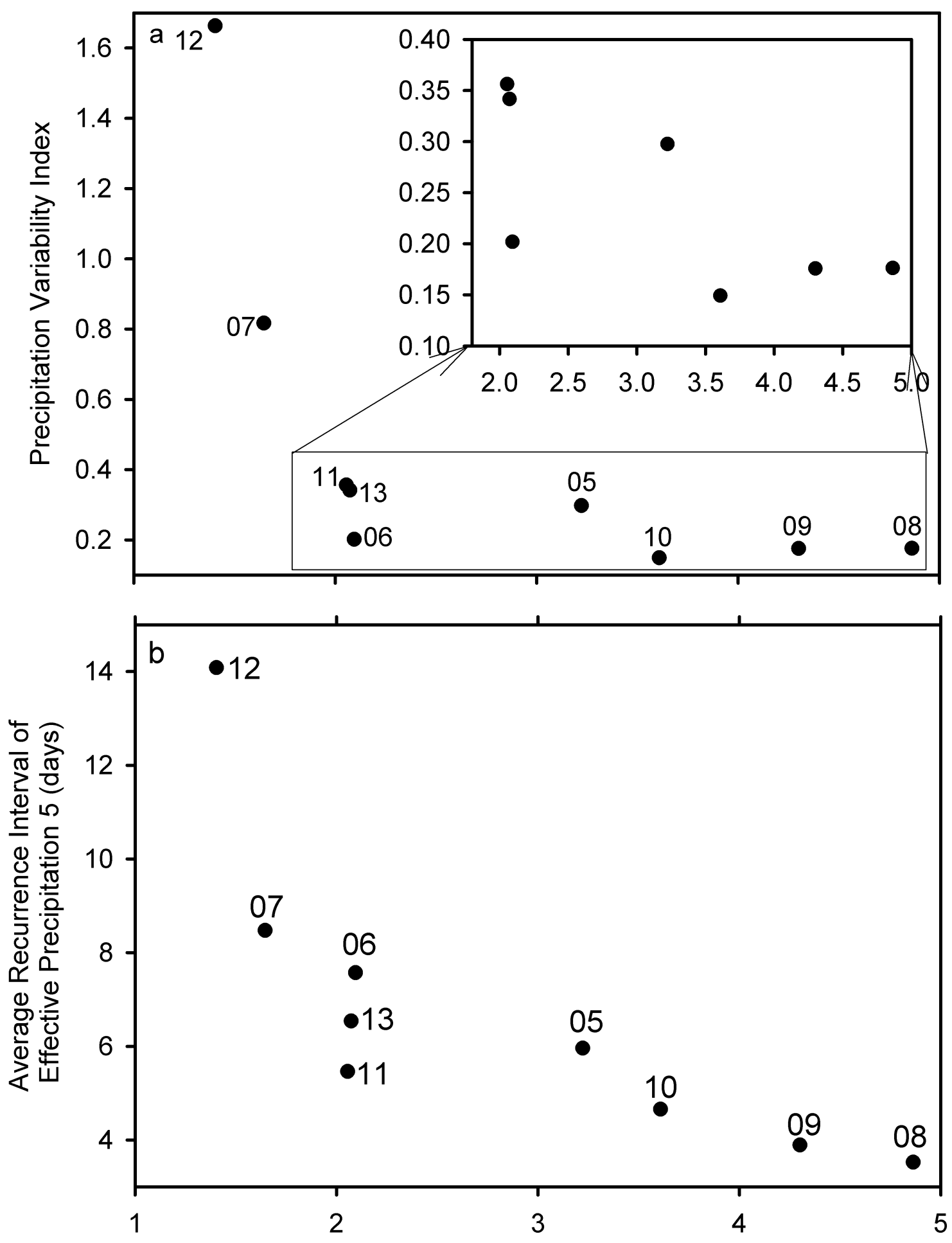

Mean Daily Precipitation Rate $\left(\mathrm{mm} \mathrm{day}^{-1}\right)$ 